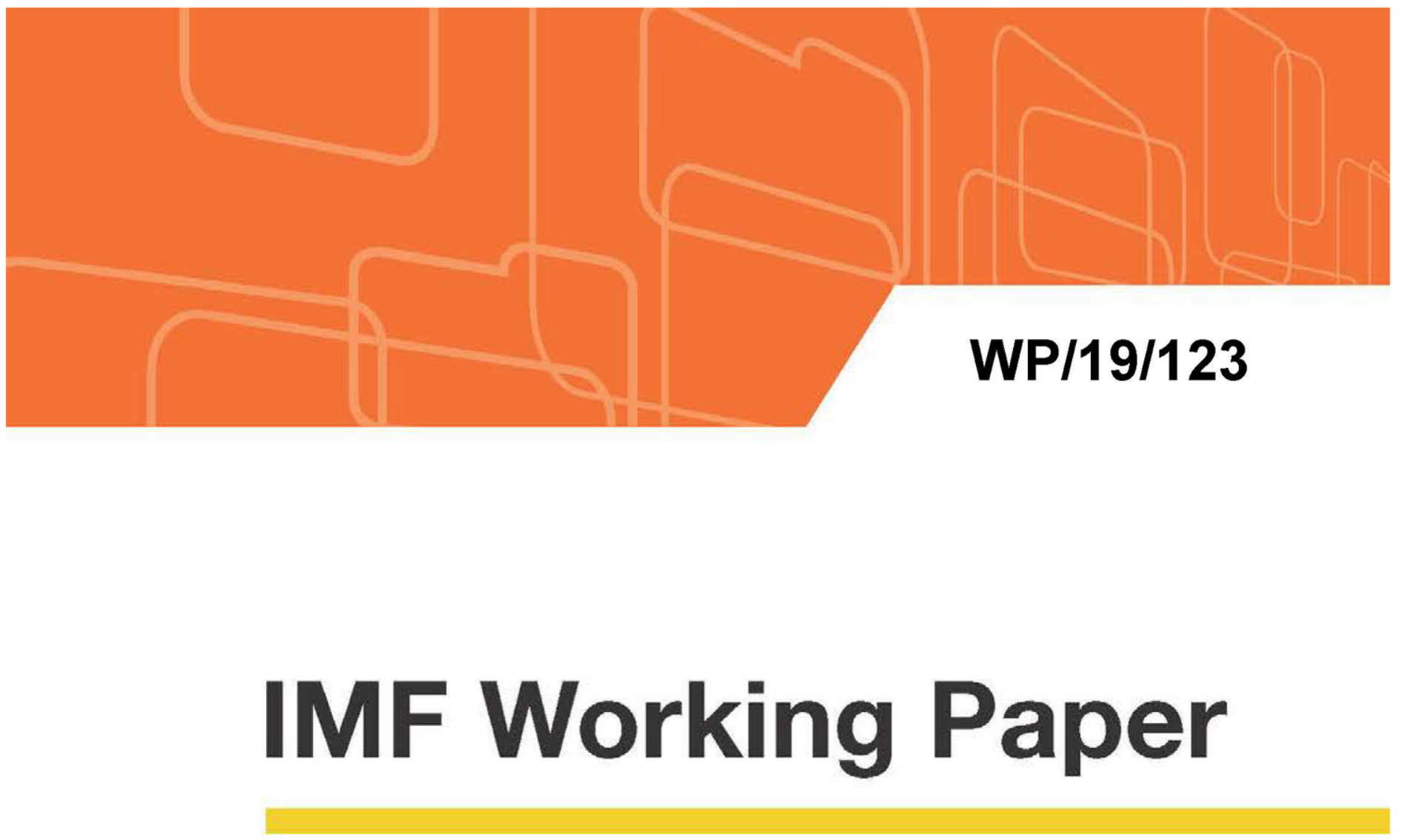

Market Regulation, Cycles and Growth in a Monetary Union

by Mirko Abbritti and Sebastian Weber

IMF Working Papers describe research in progress by the author(s) and are published to elicit comments and to encourage debate. The views expressed in IMF Working Papers are those of the author(s) and do not necessarily represent the views of the IMF, its Executive Board, or IMF management. 


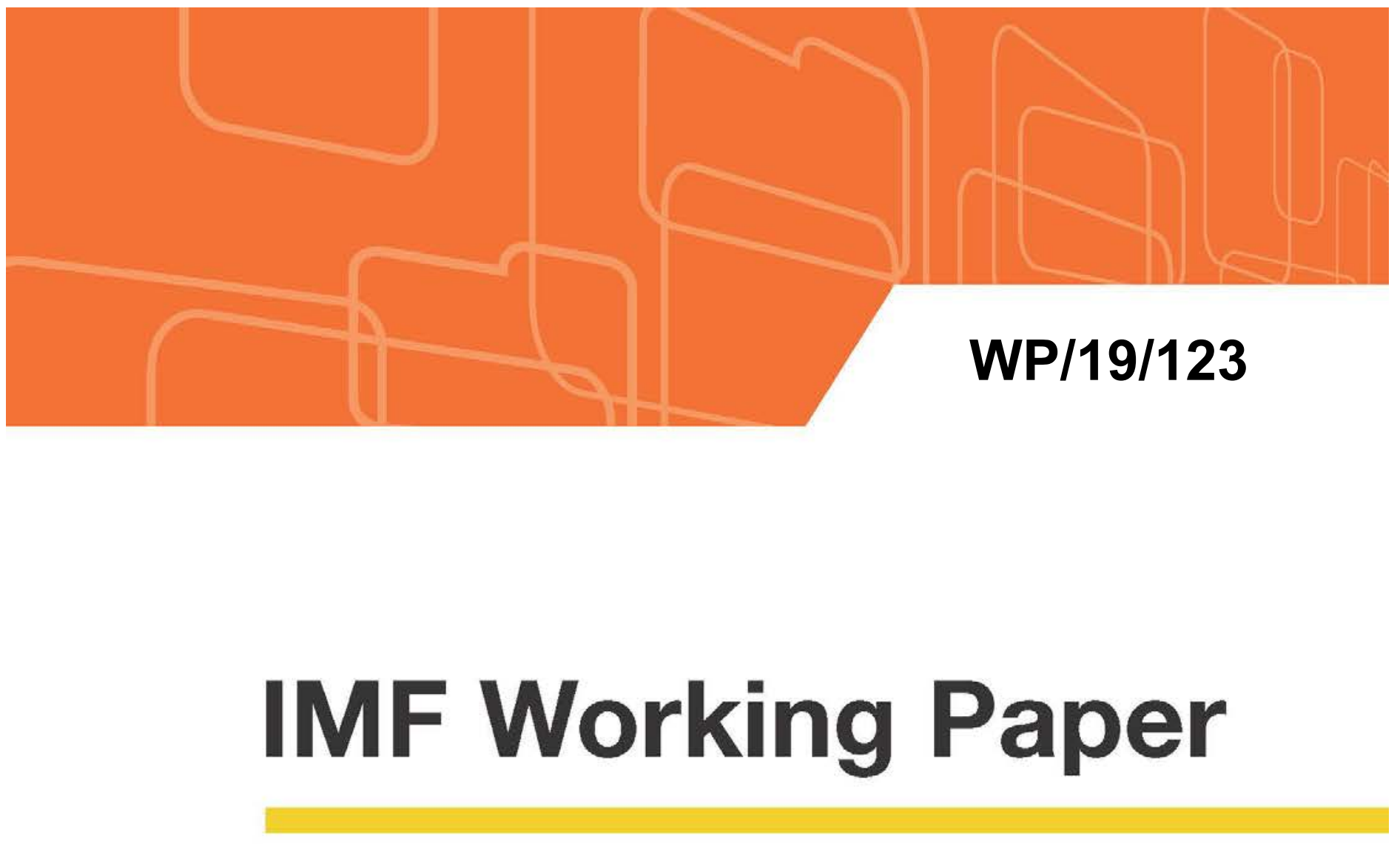

\title{
Market Regulation, Cycles and Growth in a Monetary Union
}

\author{
by Mirko Abbritti and Sebastian Weber
}

IMF Working Papers describe research in progress by the author(s) and are published to elicit comments and to encourage debate. The views expressed in IMF Working Papers are those of the author(s) and do not necessarily represent the views of the IMF, its Executive Board, or IMF management.

I N T E R N A T I O N A L M O N E T A R Y F U N D 


\title{
IMF Working Paper
}

European Department

\section{Market Regulation, Cycles and Growth in a Monetary Union \\ Prepared by Mirko Abbritti and Sebastian Weber ${ }^{\dagger}$}

Authorized for distribution by Peter Dohlman

June 2019

\begin{abstract}
IMF Working Papers describe research in progress by the author(s) and are published to elicit comments and to encourage debate. The views expressed in IMF Working Papers are those of the author(s) and do not necessarily represent the views of the IMF, its Executive Board, or IMF management.
\end{abstract}

\begin{abstract}
We build a two-country currency union DSGE model with endogenous growth to assess the role of cross-country differences in product and labor market regulations for long-term growth and for the adjustment to shocks. We show that with endogenous growth, there is no reason to expect real income convergence. Large shocks, through endogenous TFP movements, can lead to permanent changes of output and real exchange rates. Differences are exacerbated when member countries have different product and labor market regulations. Less regulated economies are likely to have higher trend growth and recover faster from negative shocks. Results are consistent with higher inflation, lower employment and disappointing TFP growth rates experienced in the less reform-friendly euro area members.
\end{abstract}

JEL Classification Numbers: F45, F43, O43, O11

Keywords: Currency union, endogenous growth, labor and product market regulation Author's E-Mail Address: Mirko Abbritti mabbritti@unav.es; and Sebastian Wber sweber@imf.org

\footnotetext{
$\dagger$ Part of this research was conducted while both authors were at the ECB. We are very grateful to Robert Anderton, Nathanial Arnold, John Bluedorn, Agostino Consolo, Romain Duval, Isabel Vansteenkiste and seminar participants at the ECB, the IMF, the 2nd Workshop on Structural Reforms in the EU, the 1st Workshop of the Spanish Macroeconomics Network and the Universitá degli Studi di Perugia for helpful comments and suggestions. The views expressed are those of the authors and do not necessarily reflect those of the IMF or the ECB.
} 


\section{Contents}

1 Introduction $\quad \underline{3}$

2 Market regulation, TFP and output growth in the euro area $\quad \underline{7}$

3 The Model $\quad \underline{10}$

3.1 Households ........................ . . . . . 10

3.2 Some definitions and identities . . . . . . . . . . . . $\underline{13}$

3.3 The product market .................. . . . . 13

3.3.1 Retail sector . . . . . . . . . . . . . . . $\underline{13}$

3.3.2 Wholesale sector . . . . . . . . . . . . . . $\underline{14}$

3.3.3 Intangible good sector . . . . . . . . . . . . . . . . $\underline{16}$

3.3.4 Innovation sector . . . . . . . . . . . . . . . . $\underline{16}$

3.4 The labor market . . . . . . . . . . . . . . . . . . . . 17

3.4.1 Search and matching frictions .............. . . . . $\frac{17}{18}$

3.4 .2 Wage determination .............. . . 18

3.5 Aggregate relationships . . . . . . . . . . . . . . . . . . 19

3.6 Long run equilibrium . . . . . . . . . . . . . . . . $\underline{20}$

4 Calibration $\quad \underline{21}$

5 Model properties $\quad \underline{23}$

5.1 Model fit . . . . . . . . . . . . . . . . . . . 23

5.2 Model dynamics . . . . . . . . . . . . . . . . . . 24

6 Effects of market regulation in a currency union $\quad \underline{\mathbf{2 6}}$

6.1 Regulation and steady state growth . . . . . . . . . . . . . $\underline{27}$

6.2 Regulation and business cycle dynamics . . . . . . . . . . . . . . . $\underline{29}$

6.3 Regulation and risk premium shocks . . . . . . . . . . . . $\underline{30}$

6.4 An application to the financial and sovereign debt crisis . . . . . . $\underline{30}$

7 Conclusion $\quad \underline{32}$ 


\section{List of Tables}

1 Business cycle component of macroeconomic moments . . . . . . . . . $\underline{40}$

2 Medium and low frequency component of macroeconomic moments . . $\underline{41}$

3 Steady state growth rate for different levels of regulation . . . . . . . . $\underline{42}$

4 Second moments for different levels of regulation . . . . . . . . . $\underline{43}$

\section{List of Figures}

1 Credit spreads, TFP and GDP dynamics in the euro area . . . . . . . $\underline{44}$

2 Euro area: TFP contribution to growth since $1965 \ldots \ldots$. . . . . . . 44

3 Long run relationships between regulation, TFP and growth . . . . . $\underline{45}$

4 Short and medium term dynamics of TFP . . . . . . . . . . . . $\underline{45}$

5 Home risk premium shock $(+50$ b.p. $) \ldots \ldots \ldots$. . . . . . . $\underline{46}$

6 Home risk premium shock, output and TFP dynamics . . . . . . . . . $\underline{47}$

7 Risk premium spillovers and income divergence . . . . . . . . . . . $\underline{48}$

8 Asymmetric reforms and long run dynamics . . . . . . . . . . . . . $\underline{49}$

$9 \quad$ Institutions and risk premium shocks . . . . . . . . . . . . . . $\underline{49}$

10 Heterogeneous risk premium shock and real income 2008/11 . . . . $\underline{50}$ 


\section{Introduction}

The Euro was introduced almost 20 years ago with the aim of fostering greater macroeconomic stability, prosperity and convergence. The experience of the euro area since its creation, however, has not kept up with expectations. Economic performances of many member countries were disappointing. Differences among member countries have amplified, with selected Northern European union members drifting apart from Southern members (Estrada et al., 2013). Figure 1 shows the dynamics of credit risk premiums, total factor productivity (TFP) and GDP for the euro area as a whole and for selected euro area countries. ${ }^{1}$ Three observations stand out: First, with the onset of the financial crisis, captured by the spike in risk premiums, euro area TFP has slowed down significantly and has not yet recovered. Second, both output and TFP seem to have shifted permanently to a lower level, spurring talks of hysteresis and secular stagnation. Third, the crisis has caused divergence among founding member states, as GDP and TFP are back to the old trend path in Germany and France, but appear on permanently lower paths in Spain and, especially, in Italy. The divergence among euro area members has attracted substantial public attention and has become a contentious political issue amidst the emergence of populist parties. $^{2}$

The objective of this paper is to study the potential role of different product (PMR) and labor market (LMR) regulations in explaining growth and business cycle dynamics in the euro area. To this aim, we develop a currency union DSGE model with endogenous growth and product and labor market frictions. The model differs from most existing two-country DSGE models in one key aspect: TFP growth is endogenous, and depends on the state and on the institutions of the economy. Thus, labor and product market regulations affect not only the adjustment of member countries to shocks, but also their long run growth prospects. The introduction of endogenous growth into a standard business cycle model allows for a meaningful analysis of TFP dynamics. The dichotomy between growth and cycle of most standard macroeconomic models is lifted and temporary shocks, such as the risk premium shocks experienced by many European countries in the last ten years, can lead to permanent reductions of the level of output and affect long run productivity. ${ }^{3}$ This is in line with recent evidence suggesting that severe recessions may affect permanently the output path and real income level of an economy (see e.g. Cerra and Saxena (2008), Blanchard et al. (2015), Martin et al. (2015), Romer and Romer (2018) and Bluedorn and Leigh (2018)).

To motivate and discipline the model, we first revisit some empirical regularities about the relationship between market regulation, R\&D investment and TFP dynamics in the euro area. We highlight two main findings. First, we document that less regulated

\footnotetext{
${ }^{1}$ See section 2 for details on the data sources and construction. To facilitate the comparisons across countries, both TFP and GDP are normalized to 1 in 2008q1.

${ }^{2}$ While the pre-euro area period was marked by convergence, this trend stalled after 1999 and was followed by divergence among EA-12 members in the post-crisis period. For new member states, the evidence following accession is mixed (Franks et al. 2018).

${ }^{3}$ This is particular relevant in the context of a currency union where monetary policy reacts to aggregate variables and, consequently, cushions less against asymmetric shocks.
} 
countries are characterized, on average, by higher R\&D investment rates, stronger TFP and output growth, and lower inflation rates. Second, we show that in response to risk premium shocks TFP has declined substantially in all countries, but the recovery has been faster in less regulated economies.

To reflect these empirical facts, we introduce three main elements in a two-country model. First, the labor market is modeled using search and matching frictions and Nash bargaining over sticky wages. This gives rise to involuntary unemployment and allows to capture the effects of three labor market institutions: employment protection legislation, unemployment benefits, and the labor tax wedge. Second, we assume imperfect competition in the retail goods sector. This allows us to measure product market regulation with the price mark-up of retail firms. ${ }^{4}$ And third, building on Romer (1990) and Kung and Schmidt (2015), we assume that TFP growth is endogenous and sustained by innovation through R\&D. We allow for three types of shocks: monetary policy shocks, technology shocks and risk premium shocks. Combined, these elements provide a unified framework to study the short- and long-term effects of heterogeneous product and labor market regulations on the dynamics of the monetary union.

Compared to a (nested) New Keynesian model with exogenous growth, the introduction of endogenous growth has three main effects on the dynamics of the monetary union: First, the presence of R\&D investment and intangible capital amplifies the response of key macroeconomic variables to demand shocks and helps matching the moments of the data. Second, through endogenous TFP movements large temporary shocks can lead to sizable permanent effects on TFP, output and relative prices. Third, there is no reason to expect income convergence among currency union members, when technology diffusion across countries is incomplete and growth depends on investment in R\&D. ${ }^{5}$ Even when member countries are perfectly identical, real incomes and real exchange rates can diverge permanently, because differences in past shocks and policy responses matter for long run dynamics. The mechanism of this result is straightforward: a large negative shock, such as a risk premium shock, reduces firms' profits and R\&D investment, which in turn reduce the process of intangible capital accumulation, which is ultimately the engine of long run growth. The lower stock of intangible capital shifts permanently the level of TFP and output.

Income divergence is further exacerbated when member countries have different economic structures, which affect both long-run growth and the short-run resilience to economic shocks. When reforms are implemented by one union member, their effects on the other (inactive) member crucially depend on the degree of technology spillovers across countries. ${ }^{6}$ In the absence of strong technology spillovers, asymmetric reforms imply a competitiveness effect and are beneficial only for the reforming country. In

\footnotetext{
${ }^{4} \mathrm{PMR}$ are modeled in a reduced form to keep the model as simple and tractable as possible and focus on the relevance of their effects for the interaction between endogenous growth and business cycle dynamics in a currency union.

${ }^{5}$ In the model, technology spillovers are exogenous.

${ }^{6} \mathrm{LMR}$ and PMR reforms have the expected long-run effects, with synchronized reductions in employment protection legislation, labor tax wedges, and unemployment benefits as well as reductions in the price mark-ups lifting output and consumption growth and reducing unemployment in the long-run.
} 
the reforming country, the reduction of product or labor market distortions triggers higher R\&D investment, which in turn increases TFP growth and leads to a lower inflation rate. The member that is not reforming experiences lower long-term output growth and a higher inflation rate, although unemployment and consumption growth remain broadly unaffected. For the currency union as a whole, asymmetric reforms remain beneficial, but lead to an equilibrium with long-run real income divergence. This points to the usefulness of coordinated reform efforts within a currecny union. The results change when there are strong positive technology spillovers. In this case reform efforts in one country also benefit the foreign country, because higher $\mathrm{R} \& \mathrm{D}$ investment in one country facilitates new discoveries abroad. As a consequence TFP, consumption and output growth increase in both member countries, and real income divergence is reduced.

In addition to their long-run effects, market regulations shape the short run adjustment to shocks. Following a risk premium shock the recovery of TFP is faster in an economy with less regulated product and labor markets. This happens in the model for a combination of the effect of institutions on short run dynamics (e.g. the collapse of TFP is smaller in countries with low LMR) and long run dynamics (the trend growth rate is larger in countries with low product market and labor market regulation). ${ }^{7}$

These model dynamics can capture well diverging patterns in the euro area. For instance, despite a deliberately simple calibration, the model replicates closely the behavior of TFP, output and real exchange rates in Italy and Germany around the Great Recession. Furthermore, results from the model match several empirical facts derived from the euro area data on regulation, R\&D investment, TFP growth and inflation, suggesting that the dismal performances of some Southern European countries are at least partly due to a combination of adverse shocks, unfavorable institutions and limited technological spillovers from the more technologically advanced members.

The findings of this paper are related to the literature studying the effects of the creation of the euro area on economic convergence. Recent research has analyzed different aspects of the experience of member countries in the first years of the Euro. There is little evidence of income convergence among the original member countries: in fact, there is growing evidence of divergence between early adopters of the euro, especially since the start of the financial crisis (Franks et al. 2018, Gross 2018). The synchronization of business and financial cycles has improved, but the amplitudes of those cycles have diverged. Moreover, there are growing signs that German financial cycles have become more delinked from other member countries' financial cycles (Franks et al. 2018). This has led some to ascribe the divergent patterns to the creation of the common currency. For instance, De Grauwe and Yuemei (2013) argue that the sovereign spread increase in some euro area countries in 2010-11 was delinked from fundamentals and associated with negative self-fulfilling market sentiments - not present in countries with independent monetary policy. Estrada et al. (2013) notice that following the Great Recession the increase of dispersion in unemployment rates has been much larger for euro area

\footnotetext{
${ }^{7}$ The results resemble estimates from local projections in response to a financial shock under varying degrees of product and labor market regulation.
} 
countries than for non-euro area countries. Taking a longer term view, Diaz del Hoyo et al. (2017) argue that certain member countries began to face a "convergence trap" well before the launch of the Euro. While it is still unclear whether sharing a common currency may have played a central role in accounting for income divergence inside the euro area, studies generally point to the crucial role of total factor productivity in driving real convergence/divergence in the euro area over time.

The paper is also related to the theoretical literature studying the effects of labor and product market reforms on economic activity. ${ }^{8}$ For instance, Cacciatore and Fiori (2016) introduce endogenous product creation and labor market frictions in an otherwise standard real business cycle model to study the effects of deregulation of entry costs, firing restrictions and unemployment benefits. Their work suggests that reforms can have short run recessionary effects, despite being expansionary in the long run. Cacciatore et al. (2016) study the consequences of product and labor market reforms in a two-country model with labor market frictions and producer entry. They show that the situation of the cycle and the ability of a country to access international lending matter for the dynamic effects of changes in product and labor market regulation. Cacciatore, Fiori and Ghironi (2016) extend a similar model to the case of a monetary union with sticky prices and wages, and analyze the optimal response of the common central bank. They find that international synchronization of reforms can eliminate policy trade-offs generated by asymmetric deregulation. Relatedly, Eggertsson, Ferrero and Raffo (2014) emphasize that when monetary policy is constrained by the zero lower bound, structural reforms that lower price and wage mark-ups can generate large output losses. Cacciatore et al. (2017) challenge this conclusion, by showing that in a model with explicit modeling of product and labor market dynamics the zero lower bound does not induce recessionary effects of market reforms. This happens because, in their model, reforms do not have noticeable deflationary effects. Andres, Arce and Thomas (2017) conclude that product market reforms, despite their deflationary effects, stimulate output and employment even in the short run in a model with financial constraints and endogenous deleveraging. Importantly, all these studies build on standard business cycle models with exogenous growth or no trend, complicating the analysis of the long-run growth implications of different labor and product market regulations.

The remaining sections of this paper are structured as follows. Section two presents some empirical facts on the relationship between market regulation, investment in $\mathrm{R} \& \mathrm{D}$, TFP and output growth in the euro area. Section three describes the model and section four discusses the calibration strategy. Section five compares the model dynamics with the ones of the conventional DSGE model without endogenous growth. Section six provides model simulations showing how labor and product market regulations affect short- and long-run dynamics of the currency union. Finally section seven concludes.

\footnotetext{
${ }^{8}$ Empirical studies have either focused on long-run effects, e.g. through the use of averages of dependent variables of interest across several years (e.g. Nickell 1997, Masuch et al 2016) or cyclical effects (see e.g. Abbritti and Weber (2018) and the references therein). While results on individual reforms vary, the evidence suggests that less regulated economies exhibit lower unemployment and higher output, but effects at the business cycle frequency depend on the specific reform under analysis.
} 


\section{Market regulation, TFP and output growth in the euro area}

In this section we provide some emprical observations regarding the relationships between market regulation, Research and Development (R\&D) investment, TFP, and output growth in the euro area. For this purpose we draw on the AMECO database for TFP growth and the OECD database for data on R\&D investment, employment protection legislation, product market regulation and unemployment benefit generosity.

According to European Commission estimates, TFP has been the main driver of the growth decline and growth divergence among euro area members. Figure 2 shows the contribution of capital, labor and TFP to GDP growth for the first 12 euro area member countries. GDP growth has declined substantially in the last 60 years, from more than 5 percent in the 1960s to less than 1 percent in the last decade. The decline in measured TFP has been the main cause behind the slowdown of growth, with TFP growth declining from close to 4 percent in the early $60 \mathrm{~s}$, to a meager 0.1 in the last decade. Thus, the figure suggests that if we want to understand the dismal economic performances, we need to understand TFP dynamics.

The top left panel of figure 3 shows the correlation between GDP growth and TFP growth, which is, not surprisingly, strongly positive. Variation in TFP accounts for half of the GDP growth differential among euro area members since the creation of the euro area. Thus, differences in TFP growth explain time and cross-country variation of GDP growth in the euro area.

Fact 1: TFP was the main driver of growth decline and growth divergence among member countries.

There are obviously several reasons that can explain such diverse dynamics of growth and productivity. An important factor is investment in R\&D (see e.g. Griffith et al. 2004, Cameron et al. 2005). While discoveries from research may support productivity globally, diffusion of knowledge is unlikely to be immediate and returns from innovation are likely to accrue with a home bias (Coe and Helpman 1995). The top right panel on figure 3 shows a positive relationship between investment in $\mathrm{R} \& \mathrm{D}$ as a percentage of GDP in 1999 and cumulative TFP growth between 1999 and 2015. For example, since 1999, TFP (GDP) growth in Italy and Greece has been more than 0.5 (1) percent lower than the euro area simple average. Both countries entered the euro area with the lowest level of business R\&D in 1999.

Fact 2: Countries that invested more in business RED have experienced higher TFP growth.

To understand the effect of labor and product market regulation on growth and TFP dynamics we build a composite regulation index, which is measured as the sum of standardized product market regulation index, employment protection legislation index

CInternational Monetary Fund. Not for Redistribution 
and the unemployment benefit generosity in deviation from the European average. ${ }^{9}$ The bottom left panel of figure 3 shows a negative correlation between market regulation and investment in R\&D (See also Ciriaci et al 2016). ${ }^{10}$ Similarly, countries which entered the monetary union with a less regulated product and labor market experienced higher TFP growth since the existence of the Euro (bottom right panel). The upper left panel in figure 4 suggests that this relationship is also true in a dynamic sense: countries that made stronger reform efforts, i.e. that moved toward less regulated markets, experienced a stronger acceleration in average TFP growth. Even though we made an attempt to limit possible reverse causality by using past values of $R \& D$ investment and market regulation in building these correlations, results are no evidence of causality. Nevertheless, they seem to provide a plausible underpinning for the role of the regulatory environment in supporting innovative activity and TFP growth.

Fact 3: Countries with more regulated labor and product markets have lower levels of investment in business RED and lower average TFP growth.

Member countries with higher TFP growth have in general experienced lower inflation rates (top right panel of figure 4). This is true when looking at two equal length sub-periods (2000-2008 and 2008-2016) or at the entire sample period. Notably, Greece (and to a much lesser extent Italy) appears not to follow this pattern. While the inflation rates in the sub-periods are undoubtedly driven by a multitude of factors, it is striking that even for the overall period of more than 15 years, the negative correlation between TFP and inflation remains. This suggests that part of the TFP gain (or loss) translated into lower (higher) prices as opposed to moving wages to offset TFP gains. Labor market institutions that generate wage rigidities may have contributed to this pattern.

Fact 4: Countries with higher TFP growth experienced lower average inflation rates.

These first four empirical facts analyze the medium-term performances of member countries since the inception of the Euro. Another important question is whether, and how, different market structures have affected the response of productivity and growth of member countries to shocks. The difficulty when answering these types of questions, is that no quarterly series for TFP growth for euro area member countries

\footnotetext{
${ }^{9}$ The measure is computed over the period data is available for the aggregate ETCR product market regulation, the employment protection regulation index for permanent contracts and the unemployment benefit measure for gross benefit replacement rates from the OECD. Several authors have either used interaction terms or principal components of indicators (see for instance Berger and Danninger, 2007).

${ }^{10}$ Recent research has shown that EPL and product market regulation may have quite complex and potentially ambiguous effects on innovation and $R \& D$ depending on the nature of the productive sector or the type of innovation activity affected (see, e.g., Griffith and Macartney, 2014, Griffith et. al, 2010; Amable et al., 2016, Cette et al., 2016, Franco et al., 2016 for different views). Consistently with our aggregate perspective, we focus in this paper on the average effect of market regulation on aggregate $\mathrm{R} \& \mathrm{D}$ investment and TFP growth.
} 
exist. ${ }^{11}$ We therefore derive a quarterly series of TFP that is compatible with the annual series provided by the European Commission's AMECO database. A detailed description of the computation is provided in the Annex. Using the quarterly TFP series, standard estimation techniques can be used to analyze the endogenous response of TFP to macroeconomic shocks that are realized at quarterly frequency.

We focus on a shock that affects the incentives for firms to engage in investment activities. This is captured by the spread of the euro area non-financial corporation bond market rates over sovereign rates (see Gilchrist and Mojon 2017). The variable is weakly exogenous, as individual member countries have a limited effect on the overall euro area spread. However, this assumption may be less appropriate for some larger union members. For this reason, the risk premium is regressed on its lag and the contemporaneous and lagged values of euro area inflation and GDP growth. ${ }^{12}$ The residual from this regression is used as a proxy for a risk premium shock.

We rely on local projection methods (Jorda 2005) and estimate the impulse response of the $\log$ of $T F P_{i t}\left(y_{i t}\right)$ for a panel of 11 euro area members (euro area-12 excluding Luxembourg) for the period from 1999 q1 to $2016 q 4$. The estimation equation is given by:

$$
y_{i, t+k}-y_{i, t}=\alpha_{i}^{k}+\beta^{k} Z_{t}+\gamma^{h} X_{i, t}+\varepsilon_{i, t}^{k} \quad \forall k=1, \ldots, 16
$$

where $\alpha_{i}^{k}$ stands for country fixed effects at horizon $\mathrm{k}, Z_{t}$ is the risk premium shock in time t, $X_{i, t}$ is a vector of control variables, including the lagged log level of TFP and a dummy for the year 2009, and $\varepsilon_{i, t}^{k}$ is a residual. ${ }^{13}$ The coefficients of interest are the sequence of $\beta^{k}$, which yield the impulse response of TFP to a one standard deviation risk premium shock, which corresponds to an increase of the risk premium by about 35 basis points on impact. The results of this exercise are shown in the bottom left panel of figure 4. Following the risk premium shock, TFP falls on impact, continues to decline until it reaches its low level (about 0.5 percent below its initial value) four quarters after the shock. Following a quick recovery for another four quarters, the TFP level remains below its initial position as further reversion is slow and TFP only appears to fully recover to its initial level after four years.

Extending the method to a smooth transition local projection estimation, ${ }^{14}$ we an-

\footnotetext{
${ }^{11}$ Quarterly data is mostly relevant to adequately reflect the timing of the shock. It is less relevant for the timing of the effect on R\&D investment spending and its subsequent effect on productivity. The latter may materialize with a lag, while the contemporaneous response of TFP may reflect adjustments in utilization (see, e.g., King and Rebelo, 2000).

${ }^{12}$ This is comparable to ordering the shock last in a VAR with GDP and inflation. Regressing the shock on its own lag also ensures that the shock's auto-correlation is limited, which addresses possible biases when using local projection methods.

${ }^{13}$ The inclusion of the 2009 dummy has only marginal effects on the impulse responses.

${ }^{14}$ The estimation equation is obtained by amending equation 1 by a term reflecting the probability to be in a regime of low or high market regulation (see for instance Duval and Furceri, 2018). Specifically, the estimation equation becomes:

$$
y_{i, t+k}-y_{i, t}=\alpha_{i}^{k}+\gamma^{h} X_{i, t}+F\left(R_{t-1}\right) \beta_{1}^{k} Z_{t}+\left[1-F\left(R_{t-1}\right)\right] \beta_{2}^{k} Z_{t}+\varepsilon_{i, t}^{k} \quad \forall k=1, \ldots, 16
$$

where $F\left(R_{t-1}\right)$ is a logistic function and $R_{t-1}$ is the composite indicator which defines the move from a low to a high regulation regime. The parameter governing the transition speed from high to low
} 
alyze to which extent the response of TFP varies depending on the extent of labor and product market regulation. We continue to use the composite indicator based on product and labor market regulations to distinguish between more or less regulated markets. Estimation results suggest that while the initial TFP response may be stronger in less regulated markets, more regulated markets tend to recover much more slowly towards the initial TFP trend path or even remain permanently below it (bottom right panel of figure 4$){ }^{15}$

Fact 5: Following a euro area wide risk premium shock, the TFP recovery is faster in less regulated economies.

Summing up, a simple look at the evidence of euro area countries in the last two decades seems to suggest a potentially significant effect of labor and product market regulations on both short term and medium term dynamics, with different institutions affecting both the long run growth prospects and the short run resilience of a country to shocks. Countries with more flexible market regulation experienced higher TFP growth and a faster recovery from financial shocks.

\section{The Model}

This section sets out the currency union model, featuring product and labor market regulations and endogenous growth through $\mathrm{R} \& \mathrm{D}$ accumulation. The monetary union consists of two countries, Home $(\mathrm{H})$ and Foreign $(\mathrm{F})$, of equal size (normalized to 1). Each economy, which is populated by identical, infinitely lived households, is specialized in the production of a bundle of differentiated goods. There is no migration across regions. Following Eggertsson et al. (2014), we assume the existence of a full set of transfers that completely insure against idiosyncratic risk in each country. The only traded asset across countries is a one-period nominal bond denominated in the common currency.

\subsection{Households}

The representative household in country $i(i=H$ or $F)$ is a large extended family which contains a continuum of members with names on the unit interval. Family members perfectly insure each other against fluctuations in consumption due to the employment status. Each household maximizes:

$$
\mathbb{E}_{0} \sum_{t=0}^{\infty} \beta^{t}\left[\log C_{t}+\varrho_{H t} \frac{A_{H t}}{P_{t}}\right], \quad \mathbb{E}_{0} \sum_{t=0}^{\infty} \beta^{t}\left[\log C_{t}^{*}+\varrho_{F t} \frac{A_{F t}}{P_{t}^{*}}\right]
$$

regulation regime is set consistent with a 20 percent probability of being in a high regulation regime that is present in the data starting in 1999. Years prior to the euro area creation exhibit a much higher probability of being in a high regulation regime, but are not part of the estimation sample.

${ }^{15}$ The empirical evidence suggests that TFP reacts in a hump-shaped manner to a financial shock. This could possibly derive from the adverse consequences the shock has first on utilization and subsequently on productivity enhancing investment, which in turn adversely affect TFP. 
where variables with star refer to the Foreign country. $C_{t}\left(C_{t}^{*}\right)$ denotes household's consumption and $A_{H t}\left(A_{F t}\right)$ holdings of the risk-less bond. This specification has two main features. First, as it is standard in quantitative macroeconomic models, utility is $\log$ in consumption. Second and most importantly, we incorporate bonds in the utility function to capture a preference for the safe asset (Krishnamurty and VissingJorgensen, 2012). $\varrho_{i t}$ captures a shock to liquidity demand in country $i$. Fisher (2015) shows that this shock can be thought of as a structural interpretation of the Smets and Wouters (2007)'s risk premium shock. Moreover, Anzoategui et al. (2018) show that the liquidity demand shock transmits to the economy like a financial shock. Therefore, the shock to $\varrho_{i t}$ allows us to study the implications of a risk premium shock without explicitly modeling financial frictions.

$C_{t}$ and $C_{t}^{*}$ are the composite consumption indexes for the Home and Foreign country respectively, defined as:

$$
C_{t}=\frac{\left(C_{H t}\right)^{1-\gamma}\left(C_{F t}\right)^{\gamma}}{(1-\gamma)^{1-\gamma}(\gamma)^{\gamma}}, \quad C_{t}^{*}=\frac{\left(C_{F t}^{*}\right)^{1-\gamma}\left(C_{H t}^{*}\right)^{\gamma}}{(1-\gamma)^{1-\gamma} \gamma^{\gamma}}
$$

The index of country i's consumption of the good produced in country j, $C_{j t}^{i}$, is given by the usual CES aggregator with elasticity of substitution $\epsilon>1 . \gamma \in[0,1]$ is the weight on the imported goods in the utility of private consumption; a value for $\gamma$ strictly less than $\frac{1}{2}$ reflects the presence of home bias in consumption. The optimal allocation of any given expenditures on the goods produced in a given country yields the demand functions:

$$
C_{H, z, t}^{i}=\left(\frac{P_{H, z, t}}{P_{H t}}\right)^{-\epsilon} C_{H t}^{i} \quad ; \quad C_{F, z, t}^{i}=\left(\frac{P_{F, z, t}}{P_{F t}}\right)^{-\epsilon} C_{F t}^{i}
$$

for $i=H, F\left({ }^{*}\right), z \in[0,1]$. The domestic price indexes of the Home and Foreign countries are given by:

$$
P_{H t}=\left(\int_{0}^{1}\left(P_{H, z, t}\right)^{1-\epsilon} d z\right)^{\frac{1}{1-\epsilon}} \quad ; \quad P_{F t}=\left(\int_{0}^{1}\left(P_{F, z, t}\right)^{1-\epsilon} d z\right)^{\frac{1}{1-\epsilon}}
$$

Because the law of one price holds, $P_{F t}$ represents both the price index for the bundle of goods imported from country $\mathrm{F}$ as well as F's domestic price index.

Furthermore, the optimal allocation of expenditures by country of origin implies, for Home:

$$
P_{H t} C_{H t}=(1-\gamma) P_{t} C_{t} \quad ; \quad P_{F t} C_{F t}=\gamma P_{t} C_{t}
$$

while for Foreign:

$$
P_{H t}^{*} C_{H t}^{*}=\gamma P_{t}^{*} C_{t}^{*} \quad ; \quad P_{F t}^{*} C_{F t}^{*}=(1-\gamma) P_{t}^{*} C_{t}^{*}
$$

where $P_{t}=\left(P_{H t}\right)^{(1-\gamma)}\left(P_{F t}\right)^{\gamma}$ and $P_{t}^{*}=\left(P_{H t}^{*}\right)^{\gamma}\left(P_{F t}^{*}\right)^{(1-\gamma)}$ are respectively the Home and the Foreign CPI indexes. Even under the law of one price, we may have that $P_{t} \neq P_{t}^{*}$, i.e. that PPP does not hold, because the two countries consume goods in different proportions. 
Combining all previous results, we can write total consumption expenditures by Home households as $P_{H t} C_{H t}+P_{F t} C_{F t}=P_{t} C_{t}$. Thus, conditional on the optimal allocation of expenditures, the period budget constraint is given by:

$C_{t}+\frac{A_{H t}}{P_{t}}+\frac{\psi_{B} \bar{C}_{t}}{2}\left(\frac{A_{H t}}{P_{t} \bar{C}_{t}}-\bar{a}\right)^{2}=\left(1-\tau_{H t}^{w}\right) \frac{W_{H t}}{P_{t}} L_{H t}+\left(1-L_{H t}\right) b_{H t}+R_{t-1} \frac{A_{H t-1}}{P_{t}}+D_{H t}$

where $R_{t}$ is the gross (union-wide) nominal interest rate of the nominal bond. Total household income is the sum of the real after tax wage income earned by employed family members $\left(1-\tau_{H t}^{w}\right) \frac{W_{H t}}{P_{t}} L_{H t}$, the benefits earned by the unemployed $\left(1-L_{H t}\right) b_{H t}$ and the family share of aggregate profits from firms, net of government lump-sum taxes $D_{H t}$. To ensure balanced growth, we assume that unemployment benefits grow at the same rate as the stock of intangible capital $N_{H t}^{C}$, i.e. $b_{H t}=b_{H} N_{H t}^{C} \cdot \tau_{H t}^{w}$ is a measure of the taxes on labor income (the tax wedge). Finally, as in Cacciatori et al. (2016), we introduce an intermediation cost $\frac{\psi_{B} \bar{C}_{t}}{2}\left(\frac{A_{H t}}{P_{t} \bar{C}_{t}}-\bar{a}\right)^{2}$, with $\bar{a}$ being the equilibrium level of the net foreign assets stock as percentage of consumption and $\bar{C}_{t}$ being the average consumption rate in the economy. ${ }^{16}$ As in Cacciatore et al. (2016), this cost is paid to financial intermediaries whose only function is to collect these transaction fees and rebate the revenue to households in lump-sum fashion.

Denoting by $\lambda_{H t}$ the Lagrange multiplier associated with the budget constraint and defining $a_{H t}=\frac{A_{H t}}{P_{t}}$ and $\varsigma_{H t}=\frac{\varrho_{H t}}{\lambda_{H t}}$, household's maximization yields the Euler equation:

$$
1+\psi_{B}\left(\frac{a_{H t}}{\bar{C}_{t}}-\bar{a}\right)=\mathbb{E}_{t} \beta_{t, t+1} \frac{R_{t}}{\pi_{t+1}}+\varsigma_{H t}
$$

where $\beta_{t, t+1}=\beta \frac{C_{H t}}{C_{H t+1}}$ and $\pi_{t+1}=\frac{P_{t+1}}{P_{t}}$ is the gross inflation rate. Similar conditions hold for the Foreign country. As equation (5) indicates, the liquidity demand shock $\varsigma_{H t}$ has a similar effect as an increase in risk: For a given riskless rate $R_{t}$, the increase in $\varsigma_{H t}$ induces a precautionary saving effect, as households reduce current consumption in order to satisfy the first order condition on the domestic bond, which requires a drop in the discount factor $\beta_{t, t+1}$. In turn, the decline of the discount factor raises the required return on capital and creates a spread with the riskless rate, which reduce investment in physical capital and R\&D. Therefore, the shock generates positive co-movements between investment and consumption like the ones usually experienced in economic downturns. ${ }^{17}$

\footnotetext{
${ }^{16}$ This intermediation cost is introduced in the model only to ensure the determination of the net foreign asset positions and stationary responses to temporary shocks. See, e.g., Benigno (2009) for a discussion. The intermediation cost is scaled by the average consumption rate in the economy to ensure balanced growth.

${ }^{17}$ See also, e.g., Anzoategui et al. (2018) for a discussion.
} 


\subsection{Some definitions and identities}

We define the bilateral terms of trade between Home and Foreign as the price of country F's domestically produced goods in terms of country H's:

$$
T_{t}=\frac{P_{F t}}{P_{H t}}
$$

Because the law of one price holds (i.e. $P_{F t}=P_{F t}^{*}$ and $P_{H t}=P_{H t}^{*}$ ), the CPI indexes and the domestic price levels are related according to:

$$
P_{t}=P_{H t}\left(T_{t}\right)^{\gamma} \text { and } P_{t}^{*}=P_{F t}\left(T_{t}\right)^{-\gamma}
$$

The real exchange rate is defined as the ratio between Foreign and Home CPI:

$$
Q_{t}=\frac{P_{t}^{*}}{P_{t}}=\left(T_{t}\right)^{1-2 \gamma}
$$

Union-wide variables are defined as a geometric average of Home and Foreign economic aggregates, e.g. $P_{t}^{U}=\left(P_{H t}\right)^{0.5}\left(P_{F t}\right)^{0.5}$ and $Y_{t}^{U}=\left(Y_{H t}\right)^{0.5}\left(Y_{F t}\right)^{0.5}$.

\subsection{The product market}

The production side of the monetary union builds on Kung and Schmidt (2015). There are four sectors in each economy. Monopolistically competitive retailers buy homogeneous wholesale goods and transform them one for one into differentiated retail goods at no additional cost. Firms in the perfectly competitive wholesale sector use labor, physical capital and domestic patented goods to produce the homogeneous wholesale good. Patented goods are produced in the intangible goods sector using innovations (new patents). Innovations are discovered through $R \& D$ in the innovation sector. Price rigidities, in the form of convex adjustment costs, arise in the retail sector. Search frictions together with convex wage adjustment costs exist in the wholesale sector. The main differences to Kung and Schmidt (2015) are the presence of search and matching frictions and sticky wages in the labor markets, which affect the wholesale good sector, and the presence of price rigidities which affect the retail sector.

\subsubsection{Retail sector}

Firms in the retail sector purchase wholesale goods at nominal price $P_{H t} \varphi_{H t}$ and convert them into differentiated goods sold to households and domestic firms. There is a measure one of monopolistic retailers indexed by $z$ on the unit interval, each of them producing one differentiated good, that is aggregated to become the final composite good:

$$
Y_{H t}=\left[\int_{0}^{1}\left(Y_{H, z, t}\right)^{\frac{\epsilon-1}{\epsilon}} d z\right]^{\frac{\epsilon}{\epsilon-1}}
$$

where $\epsilon$ represents the elasticity of substitution between retail goods. Retailers share the same technology, which transforms one unit of wholesale good into one unit of final 
retail good, so that $Y_{H, z, t}=Y_{H, z, t}^{W}$. We introduce nominal rigidities for retailers assuming firms face Rotemberg-style quadratic costs of adjusting prices. The representative firm chooses prices to solve the following maximization problem:

$$
\max _{P_{H, z, t}} \mathbb{E}_{0} \sum_{t=0}^{\infty} \beta^{t} \frac{\lambda_{H t}}{\lambda_{H 0}}\left[\frac{\left(1-\tau_{H t}^{p}\right) P_{H, z, t}-P_{H t} \varphi_{H t}}{P_{H t}}-\Gamma_{H, z, t}\right] Y_{H, z, t}
$$

subject to the demand function $Y_{H, z, t}=\left(\frac{P_{H, z, t}}{P_{H t}}\right)^{-\epsilon} Y_{H t}$ and the adjustment cost function $\Gamma_{H, z, t}=\frac{\psi}{2}\left(\frac{P_{H, z, t}}{P_{H, z, t-1}}-\bar{\pi}_{H}\right)^{2} \cdot \tau_{H t}^{p}$ is a policy instrument the government can use to affect the competitiveness of the retail sector. $\bar{\pi}_{H}$ is trend inflation. In equilibrium, assuming symmetry, the first order conditions for retail firms earn a Phillips curve:

$$
\Gamma_{H t}^{\prime} \pi_{H t}=\epsilon\left(\varphi_{H t}+\Gamma_{H t}\right)-(\epsilon-1)\left(1-\tau_{H t}^{p}\right)+\mathbb{E}_{t} \beta \frac{\lambda_{H t+1}}{\lambda_{H t}} \frac{Y_{H t+1}}{Y_{H t}}\left[\Gamma_{H t+1}^{\prime} \pi_{H t+1}\right]
$$

Notice that under flexible prices $\left(\Gamma_{H t}=\Gamma_{H t}^{\prime}=0\right)$, optimal price setting requires:

$$
\varphi_{H t}=\frac{\epsilon-1}{\epsilon}\left(1-\tau_{H t}^{p}\right)
$$

\subsubsection{Wholesale sector}

Each firm in the wholesale sector combines physical capital $\left(K_{H t}\right)$, labor $\left(L_{H t}\right)$ and a composite of patented goods $\left(G_{H t}\right)$ to produce according to the following technology:

$$
Y_{H t}^{W}=\left(\left(Z_{H t} L_{H t}\right)^{1-\alpha}\left(K_{H t}\right)^{\alpha}\right)^{1-\xi} G_{H t}^{\xi}
$$

where $Z_{H t}$ is an exogenous $\mathrm{AR}(1)$ technology shock. Following, Kung and Schmidt (2015) and Gruning (2017), the composite of patented goods is defined according to the CES aggregator:

$$
G_{H t}=\left[\left(\int_{0}^{N_{H t}}\left(X_{H, k, t}\right)^{v} d k\right)\right]^{\frac{1}{v}}
$$

where $N_{H t}$ is the number of patents used in period $t$ and $X_{H, k, t}$ is the amount of the domestically produced patented good $k$ used at Home. $1 /(1-v)$, with $v<1$, is the elasticity of substitution between varieties of patents. The law of motion of physical capital is:

$$
K_{H t+1}=\left(1-\delta_{K}\right) K_{H t}+I_{H t}
$$

In order to find a worker, firms must actively search for workers in the unemployment pool. The cost of posting a vacancy is $\kappa_{t}=\kappa N_{H t}$, where $N_{H t}$ is the stock of intangible capital available in the domestic economy. The number of workers available for production in each wholesale firm is:

$$
L_{H t}=\left(1-s_{H}\right) L_{H t-1}+q_{H t} v_{H t}
$$


where $s_{H}$ is the separation rate, $v_{H t}$ is the number of vacancies the firm posts and $q_{H t}$ the probability of filling the vacancy. Moreover, we assume that wholesale firms face quadratic costs of changing nominal wages:

$$
c_{H t}^{w}\left(\pi_{H t}^{W}\right)=\frac{\phi^{w}}{2}\left(\pi_{H t}^{W}-g_{H}^{W}\right)^{2}
$$

where $\pi_{H t}^{W}=W_{H t} / W_{H t-1}$ denotes gross wage inflation and $g_{H}^{W}$ is the steady state wage inflation rate.

Wholesale firms sell their goods to retailers at given relative price $\varphi_{H t}$ and choose capital, labor, investment and patented goods to maximize shareholder value:

$$
\max \mathbb{E}_{0}\left[\sum_{t=0}^{\infty} \beta_{0, t} \mathcal{D}_{d, t}\right]
$$

where firm's dividends are given by:

$$
\mathcal{D}_{d, t}=\varphi_{H t} Y_{H t}^{W}-\frac{W_{H t}}{P_{H t}} L_{H t}\left(1+c_{H t}^{w}\right)-\kappa_{t} v_{H t}-\left(1+\Phi_{K t}\right) I_{H t}-\int_{0}^{N_{H, t}} P_{H, k, t}^{I} X_{H, k, t} d k
$$

subject to the production function, the law of motions of labor, and physical capital. $\Phi_{K t}=\frac{\Theta_{I}}{2}\left(\frac{I_{H t}}{g_{H} I_{H t-1}}-1\right)^{2}$ is a standard, quadratic, investment cost function and $g_{H}$ is the steady state growth rate of investment. Maximization leads to the following Euler equation for capital accumulation:

$$
Q_{H t}=\mathbb{E}_{t} \beta_{t+1}\left[\alpha(1-\xi) \varphi_{H t+1} \frac{Y_{H t+1}^{W}}{K_{H t+1}}+\left(1-\delta_{K}\right) Q_{H t+1}\right]
$$

where $Q_{H t}$ denotes the shadow value of capital (in units of consumption):

$$
Q_{H t}=\left(1+\Phi_{K t}\right)+\Phi_{K t}^{\prime} \frac{I_{H t}}{g_{H} I_{H t-1}}-\mathbb{E}_{t} \beta_{t, t+1}\left[\Phi_{K t+1}^{\prime} \frac{1}{g_{H}}\left(\frac{I_{H t+1}}{I_{H t}}\right)^{2}\right]
$$

The first order condition for vacancies equates the expected cost of filling a vacancy to the value of a filled position:

$$
\frac{\kappa_{t}}{q_{H t}}=J_{H t}
$$

where $J_{H t}$, the value of en existing relationship, consists of the revenues generated by the match, net of wages and their adjustment costs, and the expected continuation value of the job next period:

$$
J_{H t}=\varphi_{H t}(1-\alpha)(1-\xi) \frac{Y_{H t}^{W}}{L_{H t}}-\frac{W_{H t}}{P_{H t}}\left(1+c_{H t}^{w}\right)+\mathbb{E}_{t}\left[\beta_{t+1}\left(1-s_{H}\right) J_{H t+1}\right]
$$

Finally, the wholesale firm's demand for patented good $k$ is determined by:

$$
X_{H, k, t}\left(P_{H, k, t}^{I}\right)=\left(\xi \frac{\varphi_{H t} Y_{H t}^{W}}{G_{H t}^{v} P_{H, k, t}^{I}}\right)^{\frac{1}{1-v}}
$$

where the price $P_{H, k, t}^{I}$ is taken as given by the single wholesale firm. 


\subsubsection{Intangible good sector}

In each country, a set of monopolistic competitive firms produce a differentiated good transforming one unit of the final retail good into one unit of their patented good. Formally, monopolists solve the following static maximization problem:

$$
\max _{P_{H, k, t}^{I}} \Pi_{H, k, t}^{I}=\max _{P_{H, k, t}^{I}} P_{H, k, t}^{I} X_{H, k, t}\left(P_{H, k, t}^{I}\right)-X_{H, k, t}\left(P_{H, k, t}^{I}\right)
$$

subject to the demand schedules $X_{H, k, t}\left(P_{H, k, t}^{I}\right)$ set by wholesale producers. In equilibrium, patented goods producers set the price as a constant mark-up over marginal costs (which are equal to unity under our assumptions):

$$
P_{H, k, t}^{I}=\frac{1}{v}
$$

and total profits depend on the demand for patented goods and are thus pro-cyclical (as in the data):

$$
\Pi_{H, k, t}^{I}=\left(\frac{1}{v}-1\right) X_{H, k, t}
$$

\subsubsection{Innovation sector}

In each country, innovations (new patents) are developed by conducting R\&D. Innovators use domestic retail goods as input and sell their innovation to patent producers. Assuming perfect competition, the price of an innovation equals its value to patent producers, $V_{H, k, t}$.

The number of innovations evolves according to:

$$
N_{H, t+1}=\vartheta_{H, t} S_{H, t}+\left(1-\delta_{N}\right) N_{H, t}
$$

where $S_{H, t}$ is the R\&D expenditure, $\delta_{N}$ is the patent obsolescence rate and $\vartheta_{H, t}$ represents the productivity of the R\&D sector, which is taken as given by innovating firms. For the Home country, its functional form is:

$$
\vartheta_{H, t}=\chi\left(\frac{S_{H t}}{N_{H t}}\right)^{\varkappa-1}\left(\frac{S_{F t}}{N_{F t}}\right)^{\sigma_{R}}
$$

where $\chi>0$ and $\varkappa \in[0,1]$ is the elasticity of innovations with respect to domestic $R \& D$. This specification allows for two main effects: First, following Kung and Schmidt (2015), it implies decreasing marginal returns to domestic R\&D investments, $\partial \vartheta_{H} / \partial S_{H}<0$ (a congestion effect). Second, by allowing for a direct effect of foreign R\&D intensity on the productivity of domestic $\mathrm{R} \& \mathrm{D}$, it allows us to capture the presence of positive knowledge spillovers $\left(\sigma_{R}>0\right)$ or negative congestion externalities $\left(\sigma_{R}<0\right)$, due e.g. to negative business stealing effects (Bloom et al., 2013), at the union wide level. In fact, stronger R\&D investment at Foreign can have both a positive effect on domestic R\&D, by facilitating new inventions at Home, or negative effects, by increasing the difficulty of 
discovering and registering new patents. When $\sigma_{R}>0$, we are implicitly assuming that positive externalities are dominating. The opposite happens when $\sigma_{R}<0$. Therefore, this functional form captures, in a simple but effective way, the effects of different assumptions about technology spillovers. ${ }^{18}$

The main force behind the cyclicality of $R \& D$ investment is the value of innovation $V_{H, k, t}$, which is the present discounted value of the profits that innovator $k$ expects to obtain selling the new discovery:

$$
V_{H, k, t}=\Pi_{H, k, t}+\left(1-\delta_{N}\right) \mathbb{E}_{t} \beta_{t, t+1} V_{H, k, t+1}
$$

The payoffs to innovation are the discounted future profits, i.e. $\mathbb{E}_{t} \beta_{t, t+1} V_{H, k, t+1}$. Because the R\&D sector is competitive, the total amount of R\&D investment is determined by a free entry condition which equates the costs with the expected benefits of R\&D:

$$
S_{H, t}=\mathbb{E}_{t} \beta_{t, t+1} V_{H, t+1}\left(N_{H, t+1}-\left(1-\delta_{N}\right) N_{H, t}\right)
$$

Notice that this implies that, at the margin:

$$
\frac{1}{\vartheta_{H, t}}=\mathbb{E}_{t} \beta_{t, t+1} V_{H, t+1}
$$

By determining the amount of R\&D investment, this condition ultimately pins down the equilibrium growth rate in the economy. Similar conditions characterize the Foreign country, which is symmetric to the Home one.

\subsection{The labor market}

Labor markets in each country are characterized by search and matching frictions á la Diamond-Mortensen-Pissarides, which affect the choice of labor input in the wholesale sector.

\subsubsection{Search and matching frictions}

Let $m_{H t}$ denote the newly formed firm-worker matches in the Home labor market. Their number depends on the measure of vacancies $v_{H t}$ and job seekers $u_{H t}$ following a constant return to scale matching technology:

$$
m_{H t}=\bar{m}_{H} u_{H t}^{\zeta} v_{H t}^{1-\zeta},
$$

\footnotetext{
${ }^{18}$ The productivity of $\mathrm{R} \& \mathrm{D}$ can conveniently be re-written to reflect a term capturing the domestic level of R\&D investment and a term reflecting catch-up to the foreign level:

$$
\vartheta_{H, t}=\chi{\widetilde{S_{H t}}}^{\sigma_{R}+\varkappa-1}\left(\frac{\widetilde{S_{F t}}}{\widetilde{S_{H t}}}\right)^{\sigma_{R}}
$$

where $\widetilde{S_{H t}}=\left(\frac{S_{H t}}{N_{H t}}\right)$ and similarly for foreign.
} 
where $\bar{m}>0, \zeta \in(0,1)$ and $u_{H t}=1-\left(1-s_{H}\right) L_{H t-1}$ is the number of searching workers at the beginning of period $t$. The probability for the firm to fill an open vacancy is

$$
q_{H t}=\frac{m_{H t}}{v_{H t}}=\bar{m} \theta_{H t}^{-\zeta}
$$

where $\theta_{H t}=\frac{v_{H t}}{u_{H t}}$ denotes labor market tightness. The probability that a worker looking for a job is matched with an open vacancy is

$$
f_{H t}=\frac{m_{H t}}{u_{H t}}=\theta_{H t} q_{H t}
$$

Employment evolves following a process of job matching and destruction. A fraction $s_{H}$ of employment relationships is destroyed in every period $t$ and a number $m_{H t}$ becomes immediately operative. The law of motion is therefore

$$
L_{H t}=\left(1-s_{H}\right) L_{H t-1}+m_{H t}
$$

For future reference, we also define (after-hiring) unemployment as the fraction of searching workers that remain unemployed after hiring takes place:

$$
u r_{H t}=1-L_{H t}
$$

Analogous relationships hold in the Foreign labor market.

\subsubsection{Wage determination}

Nominal wages are determined according to a standard Nash bargaining protocol. The main difference from the standard solution is due to the presence of wage adjustment costs in the value of an employment relationship to the firm (see equations 11 and 12). Specifically, the firm and the worker choose nominal wages to maximizes the Nash product:

$$
\arg \max _{W_{H t}}\left[\left(\tilde{J}_{H t}\right)^{1-\eta_{H}}\left(\tilde{N}_{H t}\right)^{\eta_{H}}\right]
$$

where $\eta_{H} \in(0,1)$ is the bargaining power of workers, $\tilde{J}_{H t}=\frac{P_{H t}}{P_{t}} J_{H t}$ is the value to the firm of an employment relationship in term of the final consumption goods and

$$
\tilde{N}_{H t}=\left(1-\tau_{H t}^{w}\right) w_{H t}-b_{H t}+\left(1-s_{H}\right) \mathbb{E}_{t}\left[\beta_{t+1}\left(1-f_{H t+1}\right) \tilde{N}_{H t+1}\right]
$$

is the corresponding value for the household. Similarly to Abbritti and Fahr (2013) and Arseneau and Chugh (2008), bargaining over nominal wages yields the optimal sharing rule:

$$
\omega_{t} \tilde{J}_{H t}=\left(1-\omega_{t}\right) \tilde{N}_{H t}
$$

where

$$
\omega_{t}=\frac{\eta_{H}\left(1-\tau_{H t}^{w}\right)}{\eta_{H}\left(1-\tau_{H t}^{w}\right)+\left(1-\eta_{H}\right) \tau_{t, t+1}}
$$


is the effective bargaining power of workers and $\tau_{t, t+1}$ is a time-varying term capturing the evolution of current and future expected wage adjustment costs

$$
\tau_{t, t+1}=\left\{1+c_{H t}^{w}+\frac{\partial c_{H t}^{w}}{\partial W_{H t}} W_{H t}+\left(1-s_{H}\right) \mathbb{E}_{t} \beta_{t+1}\left(\frac{T_{t}}{T_{t+1}}\right)^{-\gamma} \frac{W_{H t+1}}{\pi_{t+1}}\left(\frac{\partial c_{H t+1}^{w}}{\partial W_{H t}}\right)\right\}
$$

The implied bargained wage for the Home country can be written as:

$$
\begin{aligned}
w_{H t}= & \omega_{t}\left[\varphi_{H t} m p l_{t}-w_{H t} c_{H t}^{w}+\mathbb{C} \mathbb{V}_{t}^{F}\right] \\
& +\left(1-\omega_{t}\right)\left[b_{H t}+\tau_{H t}^{w} w_{H t}-\mathbb{C V}_{t}^{W}\right]
\end{aligned}
$$

where $m p l_{t}=(1-\alpha)(1-\xi) \frac{Y_{H t}}{L_{H t}}\left(T_{t}\right)^{-\gamma}$ denotes the marginal product of labor and $\mathbb{C V}_{t}^{W}=\mathbb{E}_{t}\left[\beta_{t+1}\left(1-s_{H}\right)\left(1-f_{H t+1}\right)\left(\tilde{N}_{H t+1}\right)\right]$ and $\mathbb{C} \mathbb{V}_{t}^{F}=\mathbb{E}_{t}\left[\beta_{t+1}\left(\frac{T_{t}}{T_{t+1}}\right)^{-\gamma}\left(1-s_{H}\right) \tilde{J}_{H t+1}\right]$ are the continuation values for the worker and the firm, respectively.

As in Arseneau and Chugh (2008) and Abbritti and Fahr (2013), wage adjustment costs distort the wage bargaining solution. Since $\partial c_{H t}^{w} / \partial W_{H t}>0$, during periods of rising wages $\tau_{t, t+1}$ increases and $\omega_{t}$ declines, dampening the fluctuations of the wage bill. The opposite happens during periods of declining wages.

\subsection{Aggregate relationships}

The resource constraint for the Home and Foreign regions are respectively:

$$
\begin{gathered}
Y_{H t}\left(1-\Gamma_{H t}\right)-c_{H t}^{w} \frac{W_{H t}}{P_{H t}} L_{H t}=C_{H t}+C_{H t}^{*}+\left(1+\Phi_{K t}\right) I_{H t}+X_{H, t} N_{H, t}+S_{H t}+\kappa_{t} v_{H t} \\
Y_{F t}\left(1-\Gamma_{F t}\right)-c_{F t}^{w} \frac{W_{F t}}{P_{F t}} L_{F t}=C_{F t}+C_{F t}^{*}+\left(1+\Phi_{K t}^{*}\right) I_{F t}+X_{F, t} N_{F, t}+S_{F t}+\kappa_{t}^{*} v_{F t}
\end{gathered}
$$

Asset market clearing requires:

$$
a_{H t}+Q_{t} a_{F t}=0
$$

Integrating the budget constraints across households in country $\mathrm{H}$, one can derive the following relationship for Home net foreign assets:

$$
a_{H t}=\frac{R_{t-1}}{\pi_{t}} a_{H t-1}+\gamma\left(Q_{t} C_{t}^{*}-C_{t}\right)
$$

We assume the central bank sets the short term nominal interest rate by reacting to the average inflation and output growth levels in the currency union. More specifically, the central bank adopts an augmented Taylor rule for the nominal interest rate:

$$
R_{t}=\left(R_{t-1}\right)^{\omega_{r}}\left[R\left(\frac{\pi_{t}^{U}}{\bar{\pi}^{U}}\right)^{\omega_{\pi}}\left(\frac{Y_{t}^{U}}{g_{u} Y_{t-1}^{U}}\right)^{\omega_{\Delta y}}\right]^{1-\omega_{r}} \varepsilon_{t}^{m}
$$


where $\pi_{t}^{U}=\left(\pi_{H t}\right)^{0.5}\left(\pi_{F t}\right)^{0.5}, Y_{t}^{U}=\left(Y_{H t}\right)^{0.5}\left(Y_{F t}\right)^{0.5}$ and $g_{u}$ is the steady state growth rate of the union. Consistently with empirical evidence, we assume that monetary policy displays a certain degree $\omega_{r}$ of interest rate smoothing. The parameters $\omega_{\pi}$ and $\omega_{\Delta y}$ are the response coefficients to inflation and output growth. The term $\varepsilon_{t}^{m}$ captures an i.i.d monetary policy shock.

Finally, inflation differentials are related to the real exchange rate according to:

$$
\frac{Q_{t}}{Q_{t-1}}=\frac{\pi_{t}^{*}}{\pi_{t}}
$$

\subsection{Long run equilibrium}

The specifications of households' preferences and firms' technologies allow finding a balanced growth path for the monetary union - even in the case in which the two regions grow at different steady state growth rates. ${ }^{19}$ Using equilibrium conditions, one can rewrite Home production as:

$$
Y_{H t}=\Xi_{H t}\left(\left(Z_{H t} L_{H t}\right)^{1-\alpha}\left(K_{H t}\right)^{\alpha}\right) N_{H t}^{\frac{1-v}{v} \frac{\xi}{1-\xi}}
$$

where $\Xi_{H t}=\left[\frac{v \xi}{\mu_{H t}}\right]^{\frac{\xi}{1-\xi}}$ and $\mu_{H t}=1 / \varphi_{H t}$ is the mark-up in the retail sector. To obtain balanced growth, we need to impose the following parametric restriction: ${ }^{20}$

$$
\frac{1-v}{v} \frac{\xi}{1-\xi}=1-\alpha
$$

If this condition is satisfied, aggregate production is homogeneous of degree one in the accumulating factors $K_{H t}$ and $N_{H t}$, and home production can be re-written as:

$$
Y_{H t}=T F P_{H t}\left(L_{H t}\right)^{1-\alpha}\left(K_{H t}\right)^{\alpha}
$$

where observed TFP is endogenously determined by:

$$
T F P_{H t}=\Xi_{H t}\left(Z_{H t} N_{H t}\right)^{1-\alpha}
$$

Productivity is increasing in the exogenous forcing process $Z_{H t}$ and in the endogenous component that depends on the domestic stock of intangible capital, $N_{H t}$, while it is inversely related to the mark-up of the retail sector, $\mu_{H t}$. The stock of intangible capital grows at an endogenous rate through the accumulation of patents, which in turn depends on the investment in R\&D:

$$
\Delta N_{H, t+1} \equiv \frac{N_{H, t+1}}{N_{H, t}}=\left(1-\delta_{N}\right)+\vartheta_{H, t} \frac{S_{H, t}}{N_{H, t}}
$$

\footnotetext{
${ }^{19}$ Because the aggregate consumption baskets are Cobb-Douglas in the domestic and foreign goods, the differences in real growth rates in consumption are exactly neutralized by the secular trend in relative prices.

${ }^{20}$ See also Kung and Schmidt (2015) and Gruning (2017).
} 
Similar relationships hold for the Foreign country:

$$
\begin{gathered}
Y_{F t}=T F P_{F t}\left(L_{F t}\right)^{1-\alpha}\left(K_{F t}\right)^{\alpha} \\
\Delta N_{F, t+1}=\left(1-\delta_{N}\right)+\vartheta_{F, t} \frac{S_{F, t}}{N_{F, t}}
\end{gathered}
$$

where TFP $P_{F t}=\Xi_{F t}\left(Z_{F t} N_{F t}\right)^{1-\alpha}$ and $\Xi_{F t}=\left\{\frac{\xi v}{\mu_{F t}}\right\}^{\frac{\xi}{1-\xi}}$.

While the growth rate of domestic production depends on the domestic stock of intangible capital, the growth rate of consumption reflects both domestic and foreign technological progress. In particular, it can be shown that, along the balanced growth path, the growth rates of consumption, $\Delta C_{t+1} \equiv \frac{C_{t+1}}{C_{t}}$ and $\Delta C_{t+1}^{*} \equiv \frac{C_{t+1}^{*}}{C_{t}^{*}}$, are proportional to the growth rates of $N_{H t}^{C}$ and $N_{F t}^{C}$, the stocks of intangible capital embodied into the aggregate consumption baskets:

$$
N_{H t}^{C}=\left(N_{H t}\right)^{1-\gamma}\left(N_{F t}\right)^{\gamma} \quad ; \quad N_{F t}^{C}=\left(N_{F t}\right)^{1-\gamma}\left(N_{H t}\right)^{\gamma}
$$

Differences in trend growth in turn translate into different steady state inflation rates, where the country growing faster has a lower inflation rate:

$$
\pi_{H}=\pi^{U}\left(\frac{\Delta N_{F}}{\Delta N_{H}}\right)^{0.5} ; \pi_{F}=\pi^{U}\left(\frac{\Delta N_{F}}{\Delta N_{H}}\right)^{-0.5}
$$

and cause a secular trend in the real exchange rate and in the terms of trade:

$$
\Delta Q=\frac{\pi^{*}}{\pi}=\frac{\Delta N_{H}^{C}}{\Delta N_{F}^{C}} ; \Delta T=\frac{\pi_{F}}{\pi_{H}}=\frac{\Delta N_{H}}{\Delta N_{F}}
$$

In summary, the model implies that member countries with higher R\&D investment enjoy higher average TFP growth, which translate into higher GDP growth, lower average inflation rates and a secular real exchange rate depreciation. Importantly, this long run equilibrium is consistent with facts 1 to 4 documented in section 2, which provide credibility to the channel proposed in this paper.

\section{Calibration}

In the baseline calibration we assume that the Home and Foreign countries are perfectly symmetric. The model is calibrated at the quarterly frequency. Parameters are set to capture the main structural features of the euro area and are close to the standard values used in the literature. The empirical moments correspond to the euro area and cover the sample from 1970q1 to 2015q4. The model is solved by second-order perturbation methods using Dynare ver. 4.5.1.

Preferences. The discount factor $\beta$ is set to 0.99 . The elasticity of substitution of retail goods is $\epsilon=11$, as in Christoffel et al. (2009) and Fahr and Smets (2010). The home bias parameter $\gamma$, representing the share of imported goods on total consumption, 
is set to 0.25 , broadly in line with the share of imports of goods and services in the euro area.

Labor markets. Following Abbritti and Mueller (2013), we set the steady state unemployment rate in each country $i$ to $u r_{i}=8$ percent, and the corresponding job finding rate to $f_{i}=0.45$. This latter value corresponds to a monthly job finding rate of 0.18 . The implied value for the job separation rate is $s_{i}=0.071$. The quarterly job filling rate is set to the standard value of $q_{i}=0.9$. The elasticity of job matches with respect to vacancies is set to 0.5 , consistently with the estimations of Petrongolo and Pissarides (2001). The workers' bargaining power is set to $\eta_{i}=0.5$, as e.g. in Blanchard and Galí (2010). Following Monacelli et al. (2010), job posting costs are chosen such that aggregate hiring costs are 0.44 percent of steady state output. The parameter $b_{i}$, capturing the value of unemployment benefits and non-work activities, and the matching efficiency parameter $\bar{m}_{i}$ are determined through steady state relationships. We get $\bar{m}_{i}=0.636$ and $b_{i}=0.024$. The latter corresponds to a benefit replacement ratio of 0.523 .

Wage and price adjustment costs. Following Fahr and Smets (2010), we set the degree of price rigidities to $\phi^{p}=45$. This is consistent with a Calvo parameter of 0.63 which represents a mean price duration of about 3 quarters. The degree of wage rigidity, $\phi^{w}$, is set to match the observed relative volatility of nominal wage inflation. We get $\phi^{w}=16$.

Production. In the wholesale sector, $\alpha$ is set to the standard value of 0.33 in order to match the average capital share. The quarterly capital depreciation rate is set to $\delta_{K}=0.02$, corresponding to an annual capital depreciation rate of 8 percent. As standard in the literature, the material share $\xi$ is set to 0.5 (see e.g. Comin and Gertler, 2006, and Kung and Schmidt, 2015). The implied inverse mark-up parameter in the intangible good sector is $v=0.6$. The investment adjustment cost is set to $\Theta_{I}=0.282$, in order to match the relative standard deviation of investment to GDP.

R\&D sector. The R\&D sector is calibrated as in Kung and Schmidt (2015). Specifically, as in Kung and Schmidt (2015) we set the patent obsolescence rate to $\delta_{N}=0.0375$ and the elasticity of new patents to $\mathrm{R} \& \mathrm{D}$ to $\varkappa=0.83$, close to the midpoint of the estimates presented by Griliches (1990). The scale parameter $\chi$ is chosen to match the average annual growth rate $g_{u}=1.6$ of the euro area economy in our sample. In the baseline calibration we abstract from technology spillovers across countries, i.e. we set $\sigma_{R}=0$. We later address, through sensitivity analysis, the effects of different degrees of technology spillovers on the currency union.

Monetary policy. We assume that the (common) central bank reacts to unionwide inflation with an elasticity $\omega_{\pi}=1.5$ and a persistence in interest rates $\omega_{r}=0.85$. As in Gilchrist et al. (2016), the response coefficient on output growth is set to $\omega_{\Delta y}=$ 0.25, the mid-point of the range suggested by Taylor (1993). The standard deviation of the monetary policy shock is set to 0.1 percent, which is in line with the estimates by Thomas and Zanetti (2009) and Christoffel et al. (2009). Consistently with the ECB's inflation objective, trend inflation is set to $\pi^{U}=2$ (annualized).

Tax rates. In the baseline calibration, we assume the presence of policy-induced distortions in the retail market and in the labor market in both countries, i.e. $\tau_{H t}^{p}=$ 
$\tau_{F t}^{p}=0.2$ and $\tau_{H t}^{w}=\tau_{F t}^{w}=0.4$. Intermediation costs are set to $\psi_{B}=0.001$.

Shock processes. We assume that Home and Foreign technology shocks are purely country-specific, i.e. uncorrelated. The persistence parameter of the technology shocks is set to $\rho_{Z i}=0.95$. The volatility of the technology shocks is set to $\sigma_{z i}=0.49$ percent in order to match the average volatility of GDP per capita. To calibrate the Home and Foreign liquidity demand shock processes, we use recent measures of risk premiums calculated by Gilchrist and Mojon (2017) for Germany, France, Italy, Spain, and the euro area. Specifically, we fit an AR(1) process to the risk premium series of non financial corporations with respect to the Bund. The data covers the sample period 1999q1-2015q4. The standard deviation of the residuals range between 0.0721 percent in the case of Germany and above 0.12 percent for Spain and Italy, while the corresponding $\mathrm{AR}(1)$ coefficient ranges between 0.816 and 0.859. Based on this evidence, we follow Abbritti and Fahr (2013) and calibrate the persistence and volatility of the Home and Foreign liquidity demand shocks to $\rho_{\varrho_{i}}=0.8$ and $\sigma_{\varrho_{i}}=0.1$ percent. The cross-correlation between Home and Foreign risk premium shocks is calibrated to match the average cross-country correlation of GDP between the four euro area member countries, which is equal to 0.65 in our sample period. We get $\sigma_{\varrho_{H}, \varrho_{F}}=0.35$.

Benchmark NK model. To understand the role of R\&D investment and intangible capital for the dynamics of the union, it will be instructive to compare the dynamics of our benchmark endogenous growth model with those of a nested New Keynesian (NK) model with exogenous growth. Specifically, the NK model we consider is a version of our model with constant R\&D investment intensity. This is equivalent to specifying an exogenous trend growth component in productivity. ${ }^{21}$ To facilitate comparison, the calibration of the benchmark NK model is identical to the one of the baseline growth model.

\section{Model properties}

The following section describes some model properties under the baseline calibration by analyzing moments at various frequencies and impulse responses to risk premium shocks. We compare data to endogenous growth model and a standard New-Keynesian model counter-part excluding the endogenous growth channel.

\section{$5.1 \quad$ Model fit}

Table 1 presents the second moments of the high frequency fluctuations of our model, its New Keynesian counter-part and the data for the euro area since 1970Q1. The high frequency component corresponds to cycles shorter than 32 quarters and is obtained by filtering the actual and simulated data with the $\mathrm{HP}(1600)$ filter.

\footnotetext{
${ }^{21}$ Kung and Schmidt (2015) follow a similar strategy to compare the asset pricing implications of growth cycles and business cycles.
} 
The model does a remarkably good job in matching most moments of the data. ${ }^{22}$ It captures well the relative volatility of TFP, employment and unemployment, and comes close to matching the relative volatility of price inflation. However, it fails in matching the relative volatility of real wages, which is larger in the data than in the model. The model also does a good job in matching the cross-correlation of most variables with output, while it underpredicts the persistence of most series.

Table 2 compares the medium and long term cycle components of the model with the ones of the data. The medium term component corresponds to cycles with periods between 32 and 100 quarters. The long term component corresponds to cycles with periods between 32 and 200 quarters. Both are obtained by filtering the data with a band-pass filter. Even though our calibration strategy does not target these moments, the model is reasonably consistent with basic medium term cycle properties of the euro area economy. In particular, the model does a good job in matching the medium and long term volatility of output, TFP, employment and unemployment. We take this as indication that the calibration of the endogenous productivity process is reasonable. The model, instead, fails to match the relatively high medium and long term volatility of wage and price inflation that we observe in the data. This discrepancy can be explained by the stable annual inflation objective of 2 percent in the model, while we observe different inflation regimes throughout our data sample with episodes of high inflation in the $70 \mathrm{~s}$ and $80 \mathrm{~s}$.

Comparing the second moments of the baseline endogenous growth model with the ones of the benchmark NK model, reveals that endogenous movements in R\&D induce a strong propagation mechanism. Switching on the endogenous growth channel, increases the volatility of output from 0.84 to 1.16 at business cycle frequency, from 1.06 to 1.51 at the medium term frequency and from 2.37 to 3.60 at the long term frequency, bringing it closer to the data. However, the simulations show that the introduction of an innovation sector leads to a reduction of wage and price inflation volatility, which are more than 10 percent lower in the model with endogenous growth.

\subsection{Model dynamics}

To further investigate the properties of the model, we focus on the responses of selected variables to an asymmetric risk premium shock and compare it with results for the New Keynesian model with exogenous growth. Figure 5 shows the impact of a large risk premium shock to the Home country. ${ }^{23}$ Following the shock and associated increase in the demand for liquid assets, domestic households increase their savings and reduce their consumption demand. These effects imply an increase in the required return on capital and lead to a fall in both home investment in physical capital and home R\&D. Due to the presence of nominal rigidities, the drops in investment and consumption

\footnotetext{
${ }^{22}$ Our calibration strategy forces the model to match the standard deviation of output and the relative volatilities of wage inflation and investment.

${ }^{23}$ The shock corresponds to an increase of the risk premium by 50 basis points (i.e. 2 percent if annualized), which is broadly in line with the increases in risk premia in countries like Spain and Italy in 2008 and 2011.
} 
lead to a drop in domestic output. The home risk premium shock is transmitted to the foreign country through direct risk premium spillover effects, movements of the terms of trade, and monetary policy. The direct spillover effects come into play because, under our calibration, a risk premium shock to one country partially spills over to the other country and leads to a reduction of consumption and investment also at Foreign. ${ }^{24}$ Moreover, the strong reduction in the prices of the home goods and associated fall in Home's terms of trade exerts deflationary pressure abroad as consumers in both countries shift their consumption towards the cheaper home goods. Finally, the central bank lowers the interest rate, which has a stimulating effect on the foreign economy. Since the first two effects dominate, the overall result is a drop of foreign inflation and a decrease of the foreign employment rate. Putting the impulse responses of the country specific variables together, a risk premium shock at Home leads to positive, and quite persistent, inflation, employment, and R\&D differentials.

Comparing the responses of the baseline growth model with the ones of the benchmark New Keynesian model, one can notice that endogenous productivity and R\&D investment magnify the negative effects of an asymmetric risk premium shock, and lead to an increase of employment and inflation differentials of almost 50 percent on impact. This amplification is a consequence of the pro-cyclicality of R\&D investment: In response to a positive risk premium shock, the profitability of R\&D investment declines and R\&D investment falls. Lower investment depresses the intangible capital stock, which in turn reduces TFP and ultimately output growth. As a result the initial contractionary shock's impact on the economy is magnified. ${ }^{25}$

In addition to its amplification effect, an even more important aspect of the model is its implication for divergence in response to temporary shocks. Figure 6 shows the effect of the home risk premium shock on the level of output and TFP. In the benchmark New Keynesian model, the risk premium shock to the Home country leads to a decrease in measured TFP on impact, because the average mark-up of the retail sector $\mu_{H t}$, which increases, enters the Solow residual (see equation 18). This causes a drop in Home GDP below the Foreign GDP level and an appreciation of the real exchange rate. However, this effect is temporary and almost completely unwound after three years. In contrast, in the model with endogenous growth the drop of measured TFP is much larger on impact, and is persistent. This is due to the presence of R\&D investment and intangible capital which has two main effects. First, the output collapse following the negative financial shock is now 1.5 percent larger. Second, the negative shock permanently shifts downward the home economy's trend. In the standard New Keynesian model with exogenous growth, the output level returns to its initial path as the shock fades.

\footnotetext{
${ }^{24}$ The currency union effects depend crucially on the degree of synchronization of shocks across different member states. Figure 7 simulates the impulse responses for different degrees of spillovers to the Foreign country comparing the results of the baseline calibration, where home and foreign risk premium shocks are weakly correlated $\left(\sigma_{\varrho_{H}, \varrho_{F}}=0.35\right)$, with the ones obtained when risk premium shocks are purely idiosyncratic $\left(\sigma_{\varrho_{H}, \varrho_{F}}=0.001\right)$ or almost perfectly correlated $\left(\sigma_{\varrho_{H}, \varrho_{F}}=0.999\right)$.

${ }^{25}$ Firm heterogeneity could have in both models (partly) offsetting effects, because the least productive firms are possibly exiting the market. This would limit the negative aggregate average effect from the fall in TFP of the surviving firms.
} 
With endogenous growth, a reversal of the shock is needed to allow for a temporarily higher growth rate and bring output back to its initial path. Hence, in the model with endogenous growth, a temporary shock can have permanent effects on relative output and real exchange rates. ${ }^{26}$ This result implies that there is no reason to expect real income convergence among member countries, because the histories of shocks and policy responses matter for long run dynamics. ${ }^{27}$

Taken together, due to the amplification and divergence effects generated by endogenous growth, the model is able to reproduce the strong GDP contraction and the shift in trend GDP that many European countries experienced after the Great Recession and the subsequent euro area debt crisis.

\section{Effects of market regulation in a currency union}

In this section we analyze how different labor and product market regulations affect the long run and short run dynamics of the currency union. ${ }^{28}$ We do so by addressing four questions in respective sub-sections: First, what are the effects of deregulation on the long-term growth prospects of currency union members? Second, what is the impact of deregulation on the volatility of its union member's economy? Third, what is the impact of regulation for the adjustment to large shocks? And fourth, to which extent can the combination of shocks and market regulation in member states contribute to explain the diverging pattern observed prior to and in the aftermath of the financial and sovereign debt crisis? To address the first three questions, we consider the effects of selected policy reforms. ${ }^{29}$ The first reform is product market deregulation. Following Eggertsson et al. (2014), we model this policy as a reduction of the tax rate of the retail sector which decreases the mark-up and increases competition. Specifically, we reduce the tax rate from $\tau_{i t}^{p}=0.2$ to $\tau_{i t}^{p}=0.185$. This translates into a reduction of the net mark-up of the retail sector of 7 percent, from 0.375 to 0.35 .

\footnotetext{
${ }^{26}$ As shown by figure 7 , the degree of shock synchronization affects the extent of income divergence in the currency union. With higher synchronization, divergence is naturally lower due to two factors: First, the direct negative effect of the shock on Foreign increases with the degree of synchronization. Second, the negative effects on employment and output in the Home country become smaller, because the common monetary policy response is stronger and thus more in line with the needs of the Home economy. Instead, when the home risk premium shock is purely idiosyncratic, foreign employment and production actually increase on impact, because the negative effects of the shock on trade are more than offset by the monetary policy reaction of the central bank.

${ }^{27}$ Because monetary policy reacts to the currency union aggregate, interest rates decline insufficiently to offset the negative effect in Home and avoid the more permanent effect. While a formal proof is beyond the scope of this paper, under a flexible exchange rate regime, monetary policy could react more to the home economy and ensure that the required return on capital is lowered; thereby stimulating savings and consumption demand to avoid a permanent reduction of the intangible capital stock.

${ }^{28}$ It is important to remark that we compare the properties of a currency union with different product and labor market institutions, but we do not study in this paper the transition dynamics from the old to the new equilibrium.

${ }^{29}$ The exercise is performed by fixing all the deep parameters of the model to their values of the baseline calibration, and allowing all the endogenous variables to adjust to changes in the policy parameters of interest.
} 
Regarding labor markets, we focus on three institutions. The first is a permanent reduction of unemployment benefits by 20 percent, which lowers the equilibrium benefits over wage ratio from 0.523 to 0.431 . The second exercise is a reduction of the tax wedge $\tau_{i t}^{w}$ from 40 to 30 percent. Finally, in the third exercise we change the overall degree of rigidity of labor market flows. Specifically, following Blanchard and Galí (2010), we define a labor market as "flexible" when the job-finding and the separation rate are high; the opposite holds in a "rigid" labor market. In practice, we change the efficiency of matches $\bar{m}_{i}$ and the exogenous separation rate $s_{i}$ such that in steady state the jobfinding rate is 0.7 and the unemployment rate is 5 percent. This implies an increase in the separation rate from $s_{i}=0.07$ to 0.12. As shown in Abbritti and Mueller (2013), this calibration of labor market rigidities captures, in a reduced form but intuitive way, the effect of lower hiring and firing costs. ${ }^{30}$

\subsection{Regulation and steady state growth}

First, we consider the effect of regulation on trend growth and the long run equilibrium of the currency union. We distinguish two cases: the case of symmetric reforms, where deregulation is implemented in both countries, and the more realistic case of asymmetric reforms, in which case we assume that there is deregulation in the Home economy but not in the Foreign economy. Results are reported in Table $3 .^{31}$

Synchronized labor or product market reforms are found to be strongly beneficial for member countries and for the union as a whole. All four reforms improve the long run growth of the economy, and lower the unemployment rate, although to different extents, and through different channels. A product market reform reducing the mark-up of retailers (column $\tau_{i}^{p}$ in the table) reduces monopolistic distortions and the relative price of retail goods. This improves the overall efficiency of the retail sector, which in turn increases the demand for wholesale and intermediate goods. The higher profit opportunities for new inventions stimulate investment in R\&D, which increases the growth rate of new patents (equation 19) and leads to an increase in TFP and output growth (equations 17 and 18). Similarly, a reduction in the tax wedge or in unemployment benefits lowers the unemployment rate and increases long run growth. To understand this result, it is useful to recall the equilibrium wage schedule of the Home country in equation 16. A reduction in the tax wedge $\tau_{H t}^{w}$ has two effects on the equilibrium wage. First, it reduces the (after-tax) wage that the worker is willing to accept. Second it increases the effective bargaining power of workers $\omega_{t}$, because firms and workers internalize, during bargaining, the effects of the tax change on wages (equation 15). The first effect dominates, and a lower tax wedge reduces the equilibrium wage. Similarly, a reduction of unemployment benefits $b_{H}$ worsens the outside option of workers, which lowers the equilibrium wage the worker is willing to accept. At the lower wage, demand for labor and production of wholesale goods increases. This in turn triggers

\footnotetext{
${ }^{30}$ Reducing employment rigidities has the same effects on inflation and output volatilities as reductions in firing costs in Zanetti (2011) and Thomas and Zanetti (2009).

${ }^{31}$ Effects of deregulation would likely be magnified by firm heterogeneity, which the model abstracts from, as higher regulation is generally associated with misallocation of resources across firms.
} 
higher demand for patented goods, which increases investment in R\&D. The higher growth in intangible capital assets triggers higher TFP and output growth. Finally, a more flexible labor market $\left(L M R_{i}\right.$ in the table) implies, by definition, a more efficient matching process and lower unemployment rate. The lower unit labor costs lead to an increase of production and make $R \& D$ investment more profitable. These patterns of the model are consistent with facts 2 and 3 of section 2, establishing that countries with higher levels of market regulation exhibit lower levels of R\&D spending and lower TFP growth (Figure 3).

When reforms are asymmetric, i.e. implemented only by the Home country, the impact on unemployment, production and growth of the Home country are qualitatively similar, but even larger. The positive effect of the reform on Home's productivity is amplified by the inaction of the Foreign country. Reforms improve home firms' competitiveness at the expenses of foreign firms, and tilt relative demand towards home goods. This effect is absent in the symmetric case. The impact on the Foreign country, crucially depends on the degree of international technology spillover. Figure 8 shows how technology spillovers affect the long run equilibrium of the Home and Foreign countries, following asymmetric reforms. ${ }^{32}$ Under the baseline calibration, in the absence of technology spillovers $\left(\sigma_{R}=0\right)$, the lower international demand lowers foreign production and investment in $\mathrm{R} \& \mathrm{D}$, and leads to a lower steady state growth rate of productivity and output. However, unemployment is only weakly affected and consumption growth is almost constant, because the lower growth rate of foreign production is compensated by an improved terms of trade and a much larger growth rate of production in the reforming country. Different steady state output growth rates translate into different inflation rates and an equilibrium depreciation of the Home country's terms of trade and real exchange rate. These patterns are consistent with the empirical observation under fact 3 , which states that countries with stricter regulation experienced lower TFP growth, and fact 4, which reveals that countries with higher TFP growth experienced lower average inflation rates (Figure 4 ). When technology spillovers are negative $\left(\sigma_{R}<0\right)$, asymmetric reforms can be beggar-thy-neighbor, i.e. detrimental for the non-reforming country. Starting from a very limited international congestion effect for innovation $\left(\sigma_{R}<-0.05\right)$, reforms in the Home country reduce not only output, but also consumption growth in the Foreign country. In addition to the negative competition effect, Foreign's return to R\&D investment is now directly reduced. Home's technological headway (as a result of lower regulation) makes additional innovation more difficult. This decreases Foreign's patent growth. Consequently, TFP and output growth in Foreign decline further. Foreign's terms of trade improvement is not sufficient anymore to compensate for its lower production. Consequently, Foreign consumption declines. When technology spillovers are positive $\left(\sigma_{R}>0\right)$ asymmetric reforms are also beneficial for the non-reforming country, because higher R\&D investment intensity at Home increases the productivity of R\&D investment in the Foreign country. The direct productivity enhancing effect of the technology spillovers more than compensate

\footnotetext{
${ }^{32}$ For visual ease, we present only the results for the product market reform $P M R_{i}$, and for the labor market reform $L M R_{i}$. The results corresponding to reforms to the tax wedge and the benefit system are qualitatively similar.
} 
the negative competition effect of the asymmetric reform. As a consequence, long run inflation, output and consumption growth differentials are strongly decreasing in $\sigma_{R}$. This suggests that in the absence of policy coordination, real income divergence among union members with different market regulation can still be reduced through policies that foster integration and enable technology spillovers.

\subsection{Regulation and business cycle dynamics}

To get an idea of the quantitative effect of labor and product market regulation in the short run, Table 4 shows how the moments of the model vary at business cycle frequency. Values are obtained by simulating the model for the different product and labor market constellations, as outlined above, and computing the standard deviation of the hp-filtered time series of the macroeconomic variables. We focus on the volatilities of inflation and employment given their importance for macroeconomic stabilization policies. $^{33}$

A lower degree of product market regulation reduces the volatility of employment but slightly increase the volatility of inflation. To understand this, notice that, up to a first order, one can write the Phillips curve of the Home country as:

$$
\hat{\pi}_{H t}=\frac{(\epsilon-1)\left(1-\tau_{H t}^{p}\right)}{\psi \bar{\pi}_{H}^{2}} \hat{\varphi}_{H t}+\beta \frac{\Delta N_{H}}{\Delta N_{H}^{C}} \hat{\pi}_{H t+1}
$$

The slope of the Phillips curve, $\frac{(\epsilon-1)\left(1-\tau_{H t}^{p}\right)}{\psi \bar{\pi}_{H}^{2}}$, is decreasing in the proxy for product market regulation, $\tau_{H t}^{p}$. Thus, lower regulation increases the elasticity of inflation to marginal costs, $\hat{\varphi}_{H t}$. As a consequence, the volatility trade-off, which we define as the ratio between the inflation volatility and employment volatility, increases after liberalizing the product market. This trade-off has an immediate economic interpretation: it represents how much inflation variation is attained for a one percent change in employment variation. In the context of monetary policy, a higher trade-off implies a lower cost in terms of employment variation from stabilizing inflation. The reform could thus be considered as dynamically efficient. ${ }^{34}$

Similarly, reforms reducing the tax wedge or the generosity of the unemployment benefits system increase inflation volatility and reduce employment volatility, leading also to an increase in the volatility trade-off. Both reforms increase the flexibility of real wages and facilitate the possibility of firms to absorb shocks using the wage channel. As a consequence, firms' share of the match surplus does not change that strongly with shocks. Hence, hiring and employment react more smoothly to changing economic conditions.

Reductions of hiring and firing costs have the opposite effect on business cycle fluctuations: the volatility of employment increases, while the responsiveness of inflation is

\footnotetext{
${ }^{33}$ The volatility of inflation is annualized.

${ }^{34}$ See also, e.g., Guilloux-Nefussi (2016) for a discussion. In recent research, Aghion, Farhi and Kharroubi (2018) and Ahn, Duval and Sever (2018) show that the effect of product market deregulation on the economy - and the stabilizing role of macroeconomic policy - may change in the presence of financial frictions that affect firms' investment funding.
} 
reduced. As a consequence, the volatility trade-off is strongly reduced in a more flexible labor market. This happens because in a flexible labor market, average job finding and separation rates are large, and changes in employment lead to small variations in labor market tightness:

$$
\hat{\theta}_{H t}=\frac{1}{s_{H}(1-\zeta)}\left\{\hat{L}_{H t}-\left(1-s_{H}\right)\left(1-f_{H}\right) \hat{L}_{H t-1}\right\}
$$

This translates into a lower elasticity of marginal costs, real wages and inflation to changes in labor, and the Phillips curve gets flatter, making the reform dynamically inefficient.

Steady-state and business cycle results suggest therefore that product market deregulation, lower labor tax wedges and unemployment benefits are steady-state and "dynamically" beneficial, and lower employment protection regulation is only steady-state beneficial as it increases the long run growth prospect of the economy, but flattens the Phillips curve making macroeconomic stabilization more costly. ${ }^{35}$

\subsection{Regulation and risk premium shocks}

In the third exercise, we analyze the endogenous growth model adjustment to a large financial shocks under different product and labor market regulations. To this end, figure 9 reports the response of home TFP to a large risk premium shock in the baseline economy and in economies with low product market rigidities or with low labor market rigidities. The left panel shows the effects of an increase in the risk premium, while the right panel the effect of a risk premium reduction. Following an increase in the risk premium (left panel), the recovery of TFP is much faster in an economy with flexible labor and product markets. Similarly, following a risk premium reduction, the more flexible economy benefits more and faster from lower rates than a sclerotic economy.

The results of the model following an increase in the risk premium resemble quite closely the local projections of the empirical part (see figure 4). This happens in the model for a combination of the effect of institutions on short run dynamics (e.g. the collapse of TFP is smaller in countries with low LMR) and long run dynamics (the trend growth rate is larger in countries with low product market and labor market regulation). The model pattern is consistent with the empirical fact 5, which documented that following a union-wide risk premium shock the TFP recovery is faster in less regulated economies.

\subsection{An application to the financial and sovereign debt crisis}

We conclude the policy simulations by applying the model to the recent experience of two union members, Germany and Italy. We analyze the effects of two distinct episodes

\footnotetext{
${ }^{35}$ In robustness exercises, we analyzed how results change when we close the R\&D investment channel, or when we change the degree of technology spillovers across countries. We find that R\&D investment and technology spillovers affect quantitatively the size and cross-correlation of business cycles across countries, but the effect of labor and product market reforms remains the same. Results are available on request.
} 
of risk premium shocks amidst the regulatory differences in the two countries. We start from two observations. First, we note that while the 2008 spike in credit spreads was symmetric across countries, in 2011 risk spreads in Italy diverged considerably from German spreads. Second, we note that, even excluding the period surrounding the two financial shocks of 2008 and 2011, the average growth rate of Germany has been slightly higher than the one of Italy. This is consistent with the lower degree of PMR in Germany: in fact, even though the OECD indicator for product market regulation declined for both countries over this period, the Germany's regulation index has been consistently lower than Italy's.

Based on these observations, we perform the following exercise. We assume that the two countries of the union differ in two aspects:

1. We assume that the degree of PMR in Germany is slightly lower than in Italy. In particular, we calibrate the policy parameters $\tau_{i}^{p}$ to match the average quarterly growth rates of GDP per capita for the period 1999q1-2015q4, excluding the years of the shocks (2008 and 2011), $g^{D E}=1.0034$ and $g^{I T}=1.0008 .{ }^{36}$ We exclude the years of the financial shocks from the computation of average growth rates to allow the model to explain diverging patterns not only with different steady state growth rates, but also with the long lasting effects of negative financial shocks. The implied policy parameters are $\tau_{D E}^{p}=0.1943$ and $\tau_{I T}^{p}=0.2057$, corresponding to gross mark-ups of $\mu^{D E}=1.365$ and $\mu^{I T}=1.385$.

2. We simulate the credit spread shocks experienced by Germany and Italy in the period from 2008 to 2011. Specifically, we model the credit spread shocks in line with the patterns observed in figure 1 for the two countries. The size and crosscorrelation of the two shocks are set to roughly match the sizes of 2008 and 2011 shocks. This implies an increase in the annualized yield by 280 basis points in 2008 and 360 basis points in 2011. The cross-correlation among the shocks in 2008 is close to complete with $\sigma_{\varrho_{I T}, \varrho_{D E}}=0.9$ while in 2011 the cross-correlation of the German yield to the Italian yield is much lower with $\sigma_{\varrho_{I T}, \varrho_{D E}}=0.30$, below the value of the baseline calibration.

Figure 10 compares the data over the ten year period from 2006 to 2016 for Germany and Italy (first column) to the respective simulated series from the model (second column). Results are shown for the credit risk spread, TFP and output growth and the real exchange rate, where the latter three variables are normalized to 1 in 2008 .

\footnotetext{
${ }^{36}$ While the literature provides some guidance, estimates linking product market regulation to GDP per capita growth vary widely. Early studies measuring simple rank correlations between PMR and GDP per capita growth and productivity growth suggest an effect of about 0.2 higher growth for one rank lower in the PMR index (Koedijk and Kremers 1996). Given the difference in PMR ranking at the time between Italy and Germany the implied estimated growth difference due to PMR was about 0.5 percent. An IMF (2004) study suggests a higher value of 1.5 percent higher GDP per capita growth on average each year in the 4 years following a drop in PMR by one standard deviation, which corresponds in the study's sample to a drop of about 0.2 in the index. Our mapping is consistent with a mid-range value between these estimates, as it implies a 1 percent higher growth rate for the average 1 point lower PMR index of Germany compared to Italy from 1999-2016 (the standard deviation in the EA-11 sample for this period is 0.8).
} 
We find that the model does a good job in replicating, at least qualitatively, the behavior of TFP, production, and real exchange rate dynamics of Germany and Italy in the last 10 years. The combination of mark-up differences and shocks cause Italian TFP and output in the model to effectively remain unchanged from 2006 to 2016, while German output is about 10 percent higher after the ten year period. While the divergence following the broadly symmetric 2008 shock is very limited in both data and model, following the asymmetric credit spread shock in 2011 the two economies start to diverge significantly and are about 10 percent apart by 2016 in both data and simulation. The endogenous bilateral real exchange rate closely traces the observed pattern in the data, at least up until 2012. ${ }^{37}$

Overall, the fit of the data with the model is quite remarkable, given the deliberate simplicity of the exercise and the fact that we consider only two shocks. We take this as confirmation that to explain the diverging economic performances of members of a currency union, one need explicit consideration of shocks and institutions, as proposed in this paper.

\section{Conclusion}

In this study, we explore how temporary shocks and differences in labor and product market regulations may have caused short- and long-term divergences in the euro area, by employing a two-country currency union DSGE model. Different to most existing New Keynesian models, growth is endogenous and a function of the state and institutions of the economy. Labor and product market regulation affect $R \& D$ investment and the accumulation of intangible capital, which ultimately determine long run TFP and output growth. The model generates dynamic adjustments to shocks and steady-state patterns that are consistent with several empirical observations for the euro area, including that countries with more regulated labor and product markets have lower levels of investment in business R\&D, lower average TFP growth and higher average inflation rates.

The model confirms findings in related studies that suggest welfare enhancing effects of union wide reductions of labor tax wedges, employment protection legislation, unemployment benefits and product market regulation. By addressing inefficiencies in the currency union, these reforms help lift employment and output. Accounting for endogenous growth, our framework provides additional findings concerning the short and long-term impact of shocks and the role of market regulation that previous models could not capture: First, the inclusion of endogenous growth amplifies business cycle

\footnotetext{
${ }^{37}$ After 2012 the model fails to capture the dynamics of the real exchange rate accurately. This is likely result of the absence of other shocks and of a financial sector in the model, which in the case of Italy was not fully transmitting the unconventional monetary policy easing into lower lending rates and thereby failed to support demand. In Germany, instead, unconventional monetary policy contributed to a much faster closing of the output gap and helped keep inflation above the one in Italy, despite higher TFP growth. Evidently, other factors also played a role throughout this ten year period which contribute to explain the remainder difference between Germany's and Italy's real income and price divergence.
} 
fluctuations and the resulting output and inflation differentials from asymmetric shocks or asymmetric market regulation. Second, while existing models suggest a return to trend, in our model large shocks can have permanent effects on the path of output. Hence, the history of shocks matters for the long-run trend. Third, when reforms are implemented only by one union member, their long-term effects crucially depend on the degree of technology spillovers across countries. In the absence of technology spillovers, asymmetric reforms imply a competitiveness effect and are only beneficial for the reforming country, calling for a coordinated approach to reforms. In the presence of meaningful technology spillovers, asymmetric reforms are beneficial for all union members. Taken together, these results imply that in a currency union with endogenous productivity and different market structures there is no guarantee for real income convergence among member countries, neither in the short nor in the long-term.

A promising extension for future research is to explore the extent to which union wide policies can address the divergence resulting from shocks and regulatory differences and how these implications differ from the conclusion derived based on standard New Keynesian models with exogenous growth. 


\section{References}

[1] Abbritti, M. and S. Fahr, (2013). "Downward wage rigidity and business cycle asymmetries," Journal of Monetary Economics, Elsevier, vol. 60(7), pages 871-886.

[2] Abbritti, M. and A. I. Mueller, (2013). "Asymmetric Labor Market Institutions in the EMU and the Volatility of Inflation and Unemployment Differentials," Journal of Money, Credit and Banking, vol. 45(6), pages 1165-1186, 09.

[3] Abbritti, M. and S. Weber, (2018). "Reassessing the Role of Labour Market Institutions for the Business Cycle", International Journal of Central Banking, vol 14(1), pages 1-34, January.

[4] Ahn, J., R. Duval and C. Sever. (Forthcoming). "Macroeconomic Policy, Product Market Competition and Growth: The Intangible Investment Channel".

[5] Aghion, P. , E. Farhi and E. Kharroubi (2018). "Monetary Policy, Product Market Competition, and Growth", mimeo.

[6] Alvarez, F. and M. Veracierto, (1999). "Labor-market policies in an equilibrium search model". NBER Macroeconomics Annual 1999 (14), 265-316.

[7] Amable, B., I. Ledezma and S. Robin, (2016). "Product market regulation, innovation, and productivity," Research Policy, Elsevier, vol. 45(10), pages 2087-2104.

[8] Andrés, J., O. Arce and C. Thomas, (2017). "Structural reforms in a debt overhang," Journal of Monetary Economics, Elsevier, vol. 88(C), pages 15-34.

[9] Anzoategui, D., D. Comin, M. Gertler and J. Martinez, (2018). "Endogenous Technology Adoption and R\&D as Sources of Business Cycle Persistence," AEJ: Macro (forthcoming).

[10] Berger, H.and S. Danninger, (2007). "The Employment Effects of Labor and Product Market Deregulation and Their Implications for Structural Reform," IMF Staff Papers, Palgrave Macmillan, vol. 54(3), pages 591-619, July.

[11] Bernal-Verdugo, L.E., D. Furceri, and D.M. Guillaume, (2012). "Labor market flexibility and unemployment: new empirical evidence of static and dynamic effects". IMF WP 12/64.

[12] Bertola, G. and R. Rogerson, (1997). "Institutions and Labour Reallocation", European Economic Review, 41:6 (1997) pp. 1147-1171.

[13] Blanchard, O., E. Cerutti and L. Summers, (2015). "Inflation and Activity - Two Explorations and their Monetary Policy Implications," NBER Working Papers 21726. 
[14] Blanchard, O. and J. Gali, (2010). "Labor Markets and Monetary Policy: A New Keynesian Model with Unemployment", American Economic Journal - Macroeconomics, 2 (April 2010):1-30.

[15] Blanchard, O. and F. Giavazzi, (2003). "Macroeconomic Effects of Regulation and Deregulation in Goods and Labour Markets", The Quarterly Journal of Economics, 118, issue 3, p. 879-907.

[16] Blanchard O. and J. Wolfers, (2000). "The Role of Shocks and Institutions in the Rise of European Unemployment: The Aggregate Evidence", Economic Journal, vol.110, pp. C1-33.

[17] Bloom, N., M. Schankerman and J. V. Reenen, (2013). "Identifying Technology Spillovers and Product Market Rivalry," Econometrica, vol. 81(4), July, pages 1347-1393.

[18] Bluedorn, J. and D. Leigh, (2018). "Is the Cycle the Trend? Evidence From the Views of International Forecasters," IMF Working Papers 18/163, International Monetary Fund.

[19] Benigno, P. (2009)."Price Stability with Imperfect Financial Integration," Journal of Money, Credit and Banking, Blackwell Publishing, vol. 41(s1), pages 121-149, 02 .

[20] Cacciatore, M. and G. Fiori, (2016). "The Macroeconomic Effects of Goods and Labour Markets Deregulation", Review of Economic Dynamics, 2016 - vol. 20, $1-24$.

[21] Cacciatore, M. , G. Fiori and F. Ghironi, (2016). "Market Deregulation and Optimal Monetary Policy in a Monetary Union", Journal of International Economics, 2016 - vol. 99, 120-137.

[22] Cacciatore, M., R. Duval, G. Fiori and F. Ghironi, (2017). "Market Reforms at the Zero Lower Bound," IMF Working Papers 17/215, International Monetary Fund.

[23] Cacciatore, M., R. Duval, G. Fiori and F. Ghironi, (2016). "Market reforms in the time of imbalance," Journal of Economic Dynamics and Control, Elsevier, vol. 72(C), pages 69-93.

[24] Cameron, G., J. Proudman, and S. Redding, (2005). "Technological convergence, R\&D, trade and productivity growth", European Economic Review, 49, issue 3, p. $775-807$.

[25] Campolmi, A. and E. Faia, (2011). "Labor Market Institutions and Inflation Volatility in the euro area," Journal of Economic Dynamics and Control, vol. 35(5), pages 793-812, May. 
[26] Cerra, V., and S. Saxena, (2008). "Growth Dynamics: The Myth of Economic Recovery." American Economic Review, 98 (1): 439-57.

[27] Cette, G., J. Lopez \& J. Mairesse, (2016). "Market Regulations, Prices, and Productivity," American Economic Review, American Economic Association, vol. 106(5), pages 104-108, May.

[28] Christoffel, K., K. Kuester and T. Linzert, (2009). "The Role of Labor Markets for euro area Monetary Policy," European Economic Review, vol. 53(8), pages 908-936, November.

[29] Ciriaci, D., N. Grassano and A. Vezzani, (2016). "Regulation, Red Tape and Location Choices of Top R\&D Investors," European Economy - Discussion Papers 2015 - 031, European Commission.

[30] Coe, D. T., and E. Helpman, (1995). "International R\&D spillovers." European Economic Review, 39(5), 859-887.

[31] Comin, D. and M. Gertler, (2006). "Medium-Term Business Cycles." American Economic Review, 96(3): 523-551.

[32] Duval, R. and D. Furceri, (2018). "The Effects of Labor and Product Market Reforms: The Role of Macroeconomic Conditions and Policies," IMF Economic Review, Palgrave Macmillan;International Monetary Fund, vol. 66(1), pages 3169, March.

[33] Ebell, M. and C. Haefke, (2009). "Product market deregulation and the U.S. employment miracle", Review of Economic Dynamics, vol. 12, 479-504.

[34] Eggertsson, G., A. Ferrero and A. Raffo (2014). "Can structural reforms help Europe?", Journal of Monetary Economics, Elsevier, vol. 61(C), pages 2-22.

[35] Elmeskov, J., J.P. Martin, and S. Scarpetta (1998). "Key Lessons For Labour Market Reforms: Evidence From OECD Countries' Experience", Swedish Economic Policy Review, Vol. 5, No. 2, pp. 205-252.

[36] Estrada, A., J. Galí and D. López-Salido, (2013). "Patterns of Convergence and Divergence in the Euro Area," IMF Economic Review, International Monetary Fund, vol. 61(4), pages 601-630, December.

[37] Fang, L. and R. Rogerson, (2011). "Product market regulation and market work: a benchmark analysis". American Economic Journal: Macroeconomics, 3 (2), 163-188.

[38] Fahr, S. and F. Smets, (2010). "Downward Wage Rigidities and Optimal Monetary Policy in a Monetary Union," Scandinavian Journal of Economics, Wiley Blackwell, vol. 112(4), pages 812-840, December. 
[39] Fiori, G., G. Nicoletti, S. Scarpetta, and F. Schiantarelli, (2012). "Employment Effects of Product and Labour Market Reforms: Are there Synergies?", Economic Journal, 2012 - vol. 122(558), F79-F104.

[40] Franco, C.,F. Pieri and F. Venturini, (2016). "Product market regulation and innovation efficiency," Journal of Productivity Analysis, Springer, vol. 45(3), pages 299-315, June.

[41] Franks, J. R., B.B. Barkbu, R. Blavy, W. Oman and H. Schoelermann (2018) "Economic Convergence in the Euro Area: Coming Together or Drifting Apart?" IMF Working Paper 18/10.

[42] Gilchrist, S., J. Sim, R. Schoenle and E. Zakrajsek (2016). "Financial Heterogeneity and Monetary Union", manuscript.

[43] Gilchrist, S. and B. Mojon (2017). "Credit Risk in the euro area", The Economic Journal.

[44] Griffith, R., S.Redding, and J.Van Reenen, (2004). "Mapping the Two Faces of R\&D: Productivity Growth in a Panel of OECD Industries," The Review of Economics and Statistics, MIT Press, vol. 86(4), pages 883-895, November.

[45] Griffith, R. and G. Macartney, 2014. "Employment Protection Legislation, Multinational Firms, and Innovation," The Review of Economics and Statistics, MIT Press, vol. 96(1), pages 135-150, March.

[46] Griffith, R., R. Harrison and H. Simpson, 2010. "Product Market Reform and Innovation in the EU," Scandinavian Journal of Economics, Wiley Blackwell, vol. 112(2), pages 389-415, June.

[47] Griliches, Z., (1990). "Patent Statistics as Economic Indicators: A Survey". Journal of Economic Literature, Vol. 28, Issue 4, p. 1661-17.

[48] Grüning, P., (2017). "International endogenous growth, macro anomalies, and asset prices", Journal of Economic Dynamics and Control, Vol. 78, May 2017, pp. 118148.

[49] Guilloux-Nefussi, S., (2016). "Globalization, Market Structure and Inflation Dynamics," Working papers 610, Banque de France.

[50] IMF (2004). "Fostering Structural Reforms in Industrial Countries", World Economic Outlook, Chapter 3, April, IMF.

[51] IMF (2016) "Time for a supply-side boost? Macroeconomic effects of labour and product market reforms", World Economic Outlook, Chapter 3, April, IMF.

[52] Jordà, O (2005). "Estimation and Inference of Impulse Responses by Local Projections," American Economic Review, American Economic Association, vol. 95(1), pages 161-182, March. 
[53] King, R. G. and S. T. Rebelo, (2000). "Resuscitating Real Business Cycles," RCER Working Papers 467, University of Rochester - Center for Economic Research (RCER).

[54] Koedijk, K. and J. Kremers, (1996). "Market opening, regulation and growth in Europe," Economic Policy, Volume 11, Issue 23, 1 October 1996, Pages 443-467.

[55] Kung, H. and Schimdt, L. (2015), "Innovation, Growth, and Asset Prices". The Journal of Finance, 70: 1001-1037.

[56] Martin, R., T. Munyan and B. A. Wilson, (2015). "Potential Output and Recessions: Are We Fooling Ourselves?", No 1145, International Finance Discussion Papers, Board of Governors of the Federal Reserve System (U.S.).

[57] Masuch, Klaus and Moshammer, Edmund and Pierluigi, Beatrice, (2016). "Institutions, Public Debt and Growth in Europe," (September 19, 2016). ECB Working Paper No. 1963.

[58] Monacelli, T., R. Perotti and A. Trigari (2010), "Unemployment fiscal multipliers," Journal of Monetary Economics, Elsevier, vol. 57(5), pages 531-553, July.

[59] Nickell, Stephen, (1997). "Unemployment and Labor Market Rigidities: Europe versus North America," Journal of Economic Perspectives, American Economic Association, vol. 11(3), pages 55-74, Summer.

[60] Piermartini, R. and S, Rubínová, 2014. "Knowledge spillovers through international supply chains," WTO Staff Working Papers ERSD-2014-11, World Trade Organization (WTO), Economic Research and Statistics Division.

[61] Petrongolo, B. and C. A. Pissarides, (2001), "Looking into the Black Box: A Survey of the Matching Function." Journal of Economic Literature, 39(2): 390-431.

[62] Romer, P., (1990). "Endogenous Technological Change", Journal of Political Economy, 98, issue 5, p. S71-102.

[63] Romer, C., and D. Romer, (2018), "Why Some Times Are Different: Macroeconomic Policy and the Aftermath of Financial Crises," Economica, vol. 85(337), pages $1-40$, January.

[64] Thomas, C. and F. Zanetti, (2009). "Labor Market Reform and Price Stability: an Application to the euro area", Journal of Monetary Economics, Vol. 56 issue 6, p. 885-899.

[65] Zanetti, F., (2011). "Labor Market Institutions and Aggregate Fluctuations in a Search and Matching Model," European Economic Review, vol. 55(5), pages 644658 , June. 


\section{Annex 1: Derivation of quarterly TFP series}

No single source for quarterly series of TFP growth in the euro area is available. For the purpose of analyzing short-and medium term dynamics it is, however, necessary to use such a series. We follow Levy and Chen (1994) to derive the relevant series for our sample of euro area members. The method uses the annual capital stock data and exploits the capital accumulation relationship between capital stock and the corresponding investment series to estimate quarterly depreciation rates which vary over time and are derived using Newton's iteration formula. Specifically, denoting the investment of a given quarter $\mathrm{j}$ in year $\mathrm{i}$ by $I_{j, i}$ the net real capital stock is given by:

$$
K_{j, i}=\left(1-\delta_{i}\right) K_{j-1, i}+I_{j, i}
$$

where the deprecation rate in a given year is assumed to be constant. Iterating this equation to replace the net capital stock such that only end-year net capital stocks remain, yields:

$$
K_{4, i}=\left(1-\delta_{i}\right)^{\wedge} K_{4, i-1}+\sum_{k=1}^{4}\left(1-\delta_{i}\right)^{4-k} I_{k, i}
$$

The equation expresses the depreciation rate as a non-linear function of last year's and this year's annual capital stock and the real quarterly investment. ${ }^{38}$ The discount rate for a given year can, thus, be obtained by solving for $\delta_{i}$ using Newton's iteration formula. ${ }^{39}$ For the 11 euro area countries in the sample the quarterly discount factor is very stable over time, showing only some variation for Greece, Belgium and Ireland. Values are clustered around $1.5 \%$ for most countries and in remain within the interval of $1-2 \%$ across countries.

After obtaining the estimated discount factors, the recursive capital accumulation equation can be used to derive the quarterly capital stock. Once the quarterly capital stock series is computed, the quarterly TFP series can be derived using quarterly real GDP, employment,${ }^{40}$ and wage share data under the Cobb-Douglas production function assumption. $^{41}$

\footnotetext{
${ }^{38}$ This could be modified to exclude residential investment, to better capture the channel from productivity enhancing investment to TFP.

${ }^{39}$ In the case of our sample, convergence was achieved at least after 3 iterations.

${ }^{40}$ Using total hours worked instead of employment would be preferable, but is left for future extensions.

${ }^{41}$ The quarterly series of TFP is derived in a way that is compatible with the annual series provided by the European Commission's AMECO database.
} 


\begin{tabular}{|c|c|c|c|c|c|c|c|c|c|}
\hline \multicolumn{10}{|c|}{ HP-Filtered Business Cycle } \\
\hline \multirow[b]{2}{*}{ Variable } & \multicolumn{3}{|c|}{$\bar{\sigma} \sigma(x) / \sigma(y)$} & \multicolumn{3}{|c|}{$\overline{\rho(x, y)}$} & \multicolumn{3}{|c|}{$\rho\left(x_{t}, x_{t-1}\right)$} \\
\hline & $\begin{array}{c}\text { euro area } \\
\text { Data }\end{array}$ & $\begin{array}{c}\text { Baseline } \\
\text { Model }\end{array}$ & $\begin{array}{c}\text { NK } \\
\text { Model } \\
\end{array}$ & $\begin{array}{c}\text { euro area } \\
\text { Data }\end{array}$ & $\begin{array}{c}\text { Baseline } \\
\text { Model }\end{array}$ & $\begin{array}{c}\text { NK } \\
\text { Model } \\
\end{array}$ & $\begin{array}{c}\text { euro area } \\
\text { Data }\end{array}$ & $\begin{array}{c}\text { Baseline } \\
\text { Model }\end{array}$ & $\begin{array}{c}\text { NK } \\
\text { Model }\end{array}$ \\
\hline " Nominal wages & 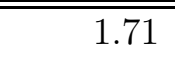 & 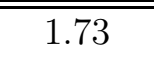 & 1.91 & "0.50 & "0.88 & "0.80 & "0.16 & "0.17 & 0.25 \\
\hline Prices & 1.07 & 0.89 & 1.03 & 0.31 & 0.94 & 0.89 & 0.22 & 0.35 & 0.46 \\
\hline Real wages & 0.84 & 0.32 & 0.38 & 0.67 & 0.87 & 0.95 & 0.92 & 0.72 & 0.75 \\
\hline Unemployment & 5.46 & 5.97 & 6.40 & -0.85 & -0.97 & -0.97 & 0.91 & 0.62 & 0.69 \\
\hline Employment & 0.43 & 0.52 & 0.56 & 0.80 & 0.97 & 0.97 & 0.95 & 0.62 & 0.70 \\
\hline Investment & 2.36 & 2.31 & 3.77 & 0.91 & 0.84 & 0.92 & 0.89 & 0.80 & 0.81 \\
\hline TFP & 0.74 & 0.68 & 0.67 & 0.93 & 0.99 & 0.98 & 0.83 & 0.37 & 0.53 \\
\hline Output & 1.00 & 1.00 & 1.00 & 1.00 & 1.00 & 1.00 & 0.88 & 0.46 & 0.58 \\
\hline$\overline{\sigma \sigma(y)}$ & 1.16 & 1.16 & "0.84 & & & & & & \\
\hline
\end{tabular}

Table 1: Business cycle component of macroeconomic moments

This table presents selected HP-filtered macroeconomic moments from the data and the baseline calibration of the model.

The standard deviations of price and wage inflations are annualized. 


\begin{tabular}{r|c|cc|c|cc}
\hline Medium and Long Term Cycle \\
\hline \hline \multirow{3}{*}{ Variable } & \multicolumn{3}{c|}{$\sigma(x) / \sigma(y)$} & \multicolumn{3}{c}{$\rho(x, y)$} \\
\cline { 2 - 7 } & euro area & Baseline & NK & euro area & Baseline & NK \\
Data & Model & Model & Data & Model & Model \\
\hline \hline Medium term component (frequency & $32-100)$ & & \\
\hline \hline Nominal wages & 7.43 & 3.85 & 4.22 & 0.27 & 0.60 & 0.64 \\
Prices & 6.02 & 2.63 & 3.24 & -0.41 & 0.41 & 0.37 \\
Real wages & 1.45 & 0.39 & 0.41 & 0.78 & 0.79 & 0.91 \\
Unemployment & 6.62 & 5.28 & 5.64 & -0.95 & -0.91 & -0.95 \\
Employment & 0.67 & 0.46 & 0.49 & 0.92 & 0.92 & 0.95 \\
Investment & 3.41 & 2.05 & 3.37 & 0.93 & 0.79 & 0.87 \\
TFP & 0.51 & 0.70 & 0.67 & 0.80 & 0.99 & 0.95 \\
Output & 1.00 & 1.00 & 1.00 & 1.00 & 1.00 & 1.00 \\
\hline$\sigma(y)$ & 1.53 & 1.51 & 1.06 & & & \\
\hline \hline Long term component (frequency 32-200) & & & \\
\hline \hline Nominal wages & 9.15 & 3.17 & 3.62 & -0.65 & 0.60 & 0.65 \\
Prices & 10.29 & 2.07 & 2.70 & -0.85 & 0.41 & 0.37 \\
Real wages & 1.14 & 0.34 & 0.37 & 0.62 & 0.76 & 0.89 \\
Unemployment & 5.20 & 5.14 & 5.59 & -0.81 & -0.91 & -0.94 \\
Employment & 0.49 & 0.45 & 0.49 & 0.91 & 0.91 & 0.94 \\
Investment & 3.60 & 1.76 & 3.02 & 0.96 & 0.74 & 0.83 \\
TFP & 0.55 & 0.72 & 0.69 & 0.90 & 0.99 & 0.96 \\
Output & 1.00 & 1.00 & 1.00 & 1.00 & 1.00 & 1.00 \\
\hline$\sigma(y)$ & 3.05 & 3.60 & 2.37 & & & \\
\hline
\end{tabular}

Table 2: Medium and low frequency component of macroeconomic moments Tha table compares data and the baseline calibration of the model. The medium term component corresponds to cycles with periods between 32 and 100 quarters and is obtained by filtering the data with a Band-pass filter. The long term component corresponds to cycles with periods between 32 and 200 quarters and is obtained by filtering the data with a Band-pass filter. 


\begin{tabular}{l|l|l|llll|llll}
\hline \multicolumn{2}{l|}{$\begin{array}{l}\text { Long Run } \\
\text { Mean }\end{array}$} & Baseline & \multicolumn{6}{|c|}{ Symmetric Reforms } & \multicolumn{4}{|c}{ Asymmetric Reforms } \\
Calibration & $\tau_{i}^{p}$ & $\tau_{i}^{w}$ & $b_{i}$ & $L M R_{i}$ & $\tau_{H}^{p}$ & $\tau_{H}^{w}$ & $b_{H}$ & $L M R_{H}$ \\
\hline \hline \multirow{2}{*}{ Union } & $\Delta y^{U}$ & $\mathbf{1 . 6 0}$ & 2.34 & 2.02 & 2.12 & 1.93 & 1.97 & 1.81 & 1.86 & 1.76 \\
& $\Delta c^{U}$ & $\mathbf{1 . 6 0}$ & 2.34 & 2.02 & 2.12 & 1.93 & 1.97 & 1.81 & 1.86 & 1.76 \\
& $u^{U}$ & $\mathbf{8 . 0 0}$ & 6.62 & 4.24 & 3.30 & 5.00 & 7.28 & 5.82 & 5.13 & 6.35 \\
& $\pi^{U}$ & $\mathbf{2 . 0 0}$ & 2.00 & 2.00 & 2.00 & 2.00 & 2.00 & 2.00 & 2.00 & 2.00 \\
\hline Home & $\Delta y^{H}$ & $\mathbf{1 . 6 0}$ & 2.34 & 2.02 & 2.12 & 1.93 & 2.68 & 2.19 & 2.34 & 2.06 \\
& $\Delta c^{H}$ & $\mathbf{1 . 6 0}$ & 2.34 & 2.02 & 2.12 & 1.93 & 2.33 & 2.00 & 2.10 & 1.91 \\
& $u^{H}$ & $\mathbf{8 . 0 0}$ & 6.62 & 4.24 & 3.30 & 5.00 & 6.51 & 4.26 & 3.32 & 5.09 \\
& $\pi^{H}$ & $\mathbf{2 . 0 0}$ & 2.00 & 2.00 & 2.00 & 2.00 & 1.28 & 1.62 & 1.53 & 1.71 \\
\hline \multirow{2}{*}{ Foreign } & $\Delta y^{F}$ & $\mathbf{1 . 6 0}$ & 2.34 & 2.02 & 2.12 & 1.93 & 1.25 & 1.43 & 1.39 & 1.47 \\
& $\Delta c^{F}$ & $\mathbf{1 . 6 0}$ & 2.34 & 2.02 & 2.12 & 1.93 & 1.61 & 1.62 & 1.63 & 1.62 \\
& $u^{F}$ & $\mathbf{8 . 0 0}$ & 6.62 & 4.24 & 3.30 & 5.00 & 8.14 & 7.94 & 7.92 & 7.93 \\
& $\pi^{F}$ & $\mathbf{2 . 0 0}$ & 2.00 & 2.00 & 2.00 & 2.00 & 2.72 & 2.38 & 2.48 & 2.29 \\
\hline Rel. prices & $\Delta T o T$ & $\mathbf{0 . 0 0}$ & 0.00 & 0.00 & 0.00 & 0.00 & 1.44 & 0.76 & 0.95 & 0.58 \\
& $\Delta R E R$ & $\mathbf{0 . 0 0}$ & 0.00 & 0.00 & 0.00 & 0.00 & 0.72 & 0.38 & 0.48 & 0.30 \\
\hline
\end{tabular}

Table 3: Steady state growth rate for different levels of regulation 


\begin{tabular}{l|l|l|l|lllll|llll}
\hline $\begin{array}{l}\text { Second moments } \\
\text { (HP-filtered) }\end{array}$ & Euro area & \multicolumn{3}{|l|}{ Baseline } & \multicolumn{3}{|c|}{ Symmetric Reforms } & \multicolumn{4}{|c}{ Asymmetric Reforms } \\
Union & $\sigma\left(\pi_{U}\right)$ & 1.25 & $\mathbf{1 . 0 3}$ & 1.06 & 1.07 & 1.08 & 0.95 & 1.05 & 1.05 & 1.06 & 0.99 \\
& $\sigma\left(L_{U}\right)$ & 0.50 & $\mathbf{0 . 6 0}$ & 0.57 & 0.46 & 0.43 & 0.90 & 0.59 & 0.53 & 0.51 & 0.75 \\
& $\sigma\left(\pi_{U}\right) / \sigma\left(L_{U}\right)$ & 2.49 & $\mathbf{1 . 7 2}$ & 1.86 & 2.33 & 2.51 & 1.06 & 1.78 & 1.98 & 2.08 & 1.32 \\
\hline \hline Home & $\sigma\left(\pi_{H}\right)$ & - & $\mathbf{1 . 1 2}$ & 1.15 & 1.16 & 1.18 & 1.03 & 1.16 & 1.18 & 1.20 & 1.02 \\
& $\sigma\left(L_{H}\right)$ & - & $\mathbf{0 . 6 7}$ & 0.63 & 0.51 & 0.47 & 0.98 & 0.63 & 0.52 & 0.48 & 0.98 \\
& $\sigma\left(\pi_{H}\right) / \sigma\left(L_{H}\right)$ & - & $\mathbf{1 . 6 7}$ & 1.83 & 2.27 & 2.51 & 1.05 & 1.84 & 2.27 & 2.50 & 1.04 \\
\hline Foreign & $\sigma\left(\pi_{F}\right)$ & - & $\mathbf{1 . 1 2}$ & 1.15 & 1.16 & 1.18 & 1.03 & 1.11 & 1.10 & 1.10 & 1.13 \\
& $\sigma\left(L_{F}\right)$ & - & $\mathbf{0 . 6 7}$ & 0.63 & 0.51 & 0.47 & 0.98 & 0.67 & 0.66 & 0.65 & 0.67 \\
& $\sigma\left(\pi_{F}\right) / \sigma\left(L_{F}\right)$ & - & $\mathbf{1 . 6 7}$ & 1.83 & 2.27 & 2.51 & 1.05 & 1.66 & 1.67 & 1.69 & 1.69 \\
\hline Differentials & $\sigma\left(\pi_{F}\right) / \sigma\left(\pi_{H}\right)$ & - & $\mathbf{1 . 0 0}$ & 1.00 & 1.00 & 1.00 & 1.00 & 0.96 & 0.93 & 0.92 & 1.11 \\
& $\sigma\left(L_{F}\right) / \sigma\left(L_{H}\right)$ & - & $\mathbf{1 . 0 0}$ & 1.00 & 1.00 & 1.00 & 1.00 & 1.06 & 1.27 & 1.35 & 0.68 \\
\hline
\end{tabular}

Table 4: Second moments for different levels of regulation 

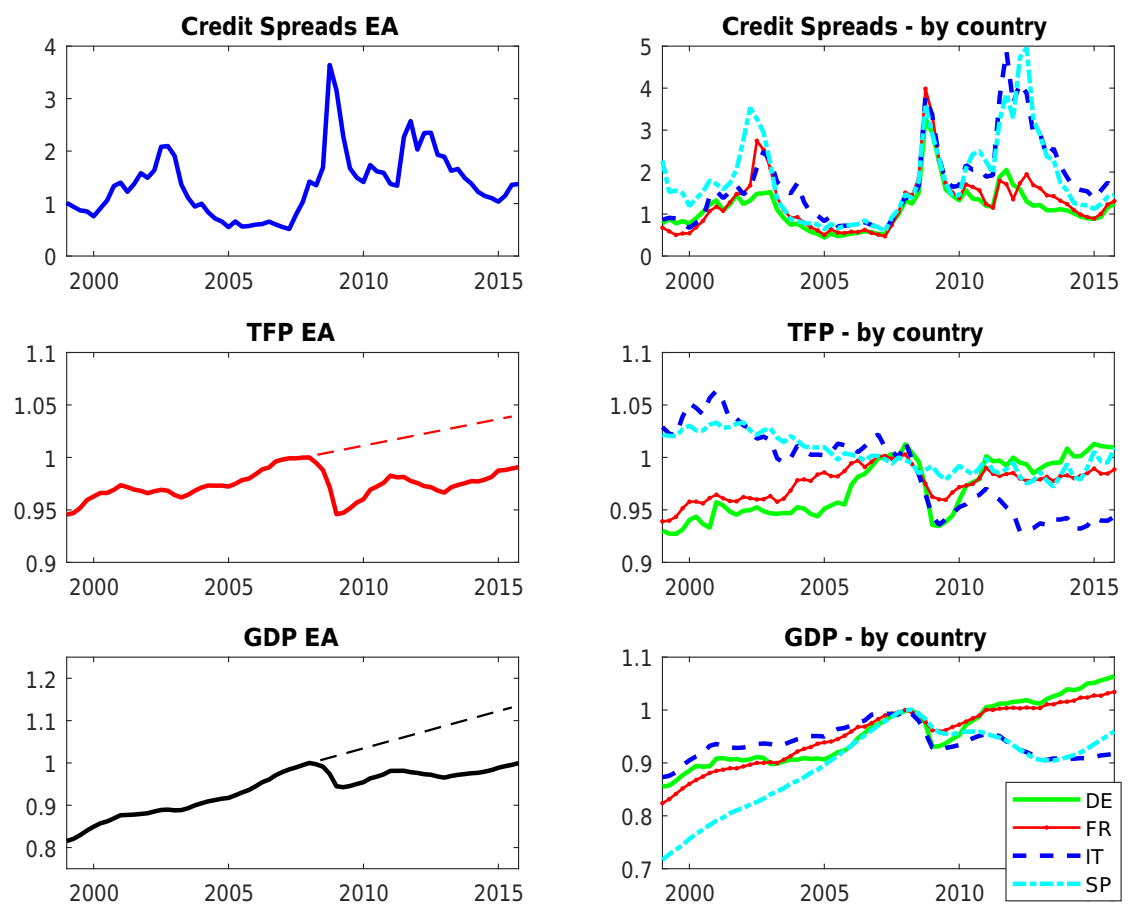

Figure 1: Credit spreads, TFP and GDP dynamics in the euro area

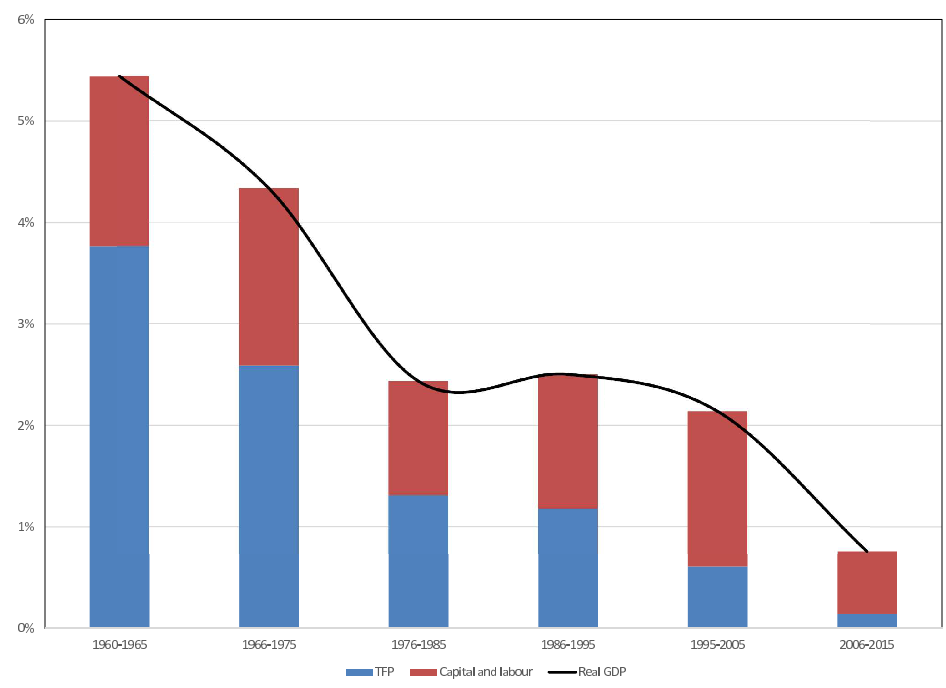

Figure 2: Euro area: TFP contribution to growth since 1965 

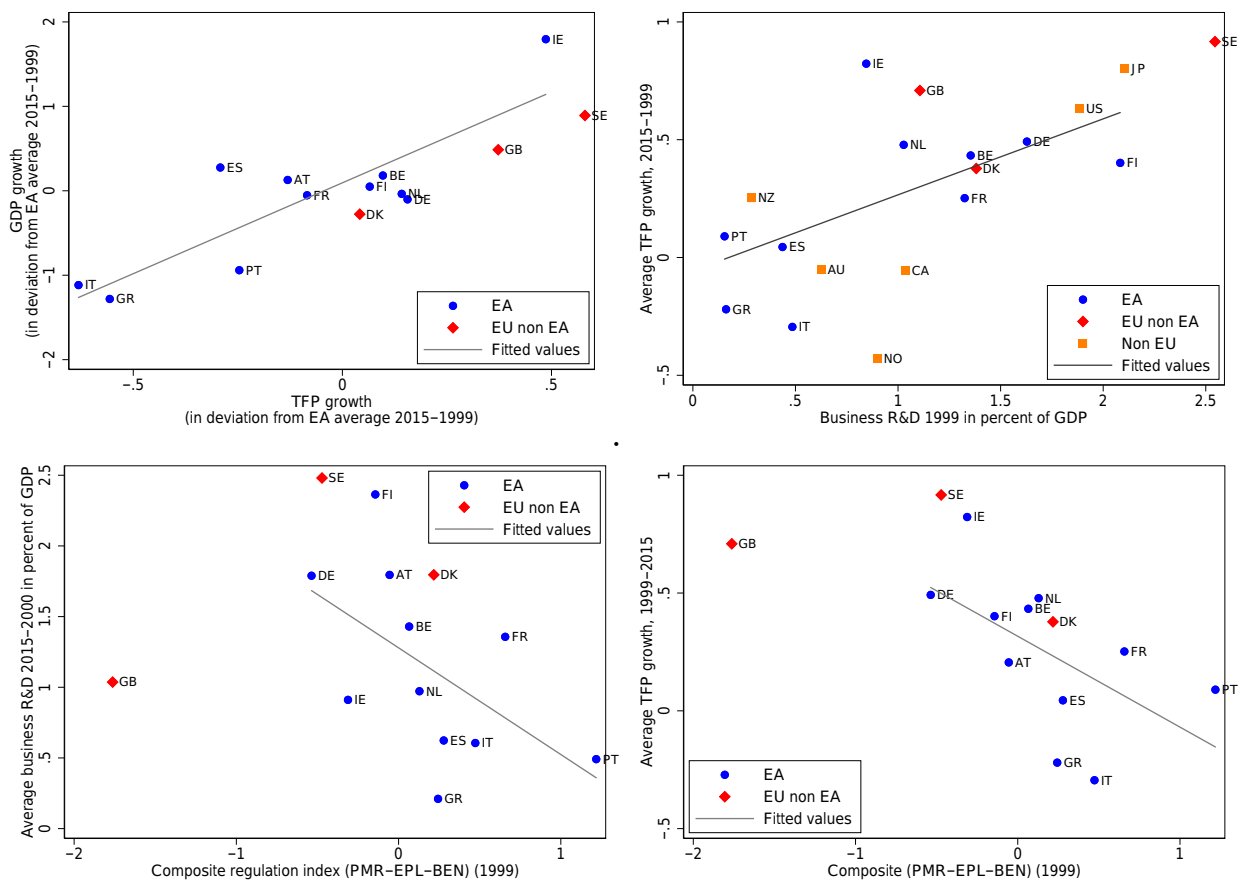

Figure 3: Long run relationships between regulation, TFP and growth
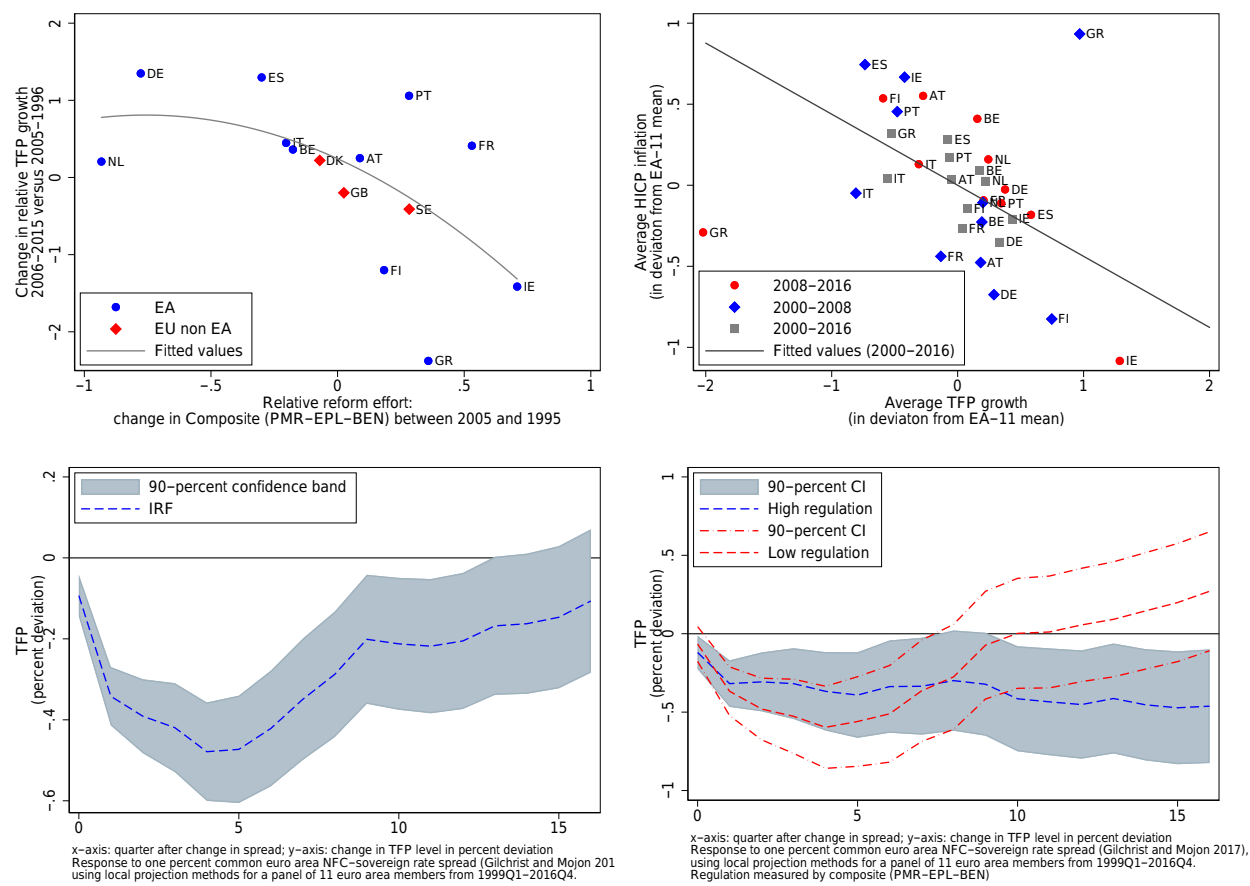

Figure 4: Short and medium term dynamics of TFP 
(a) Home inflation

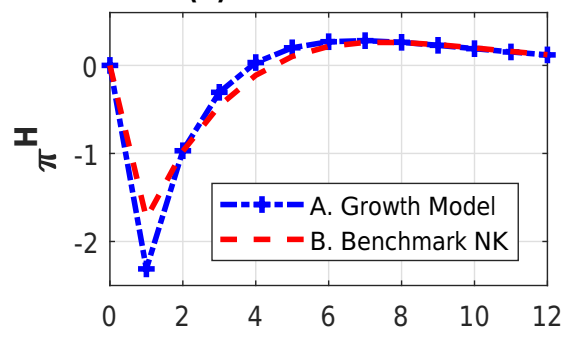

(d) Foreign inflation

ㄴ -1

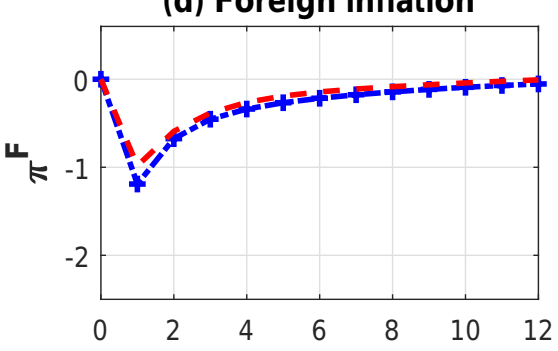

(h) inflation differentials

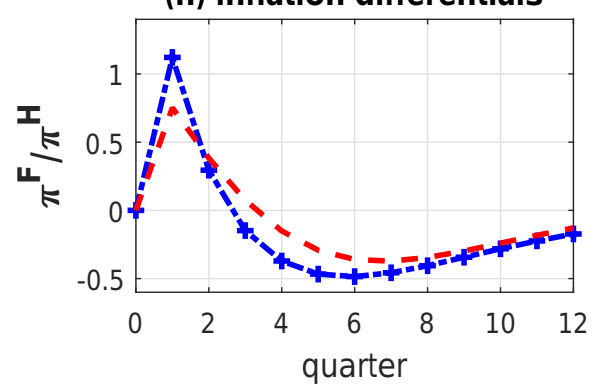

(b) Home employment

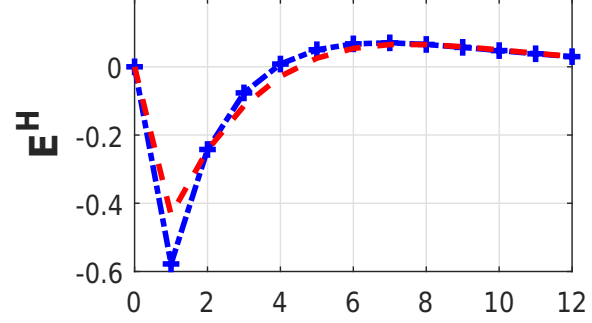

(e) Foreign employment
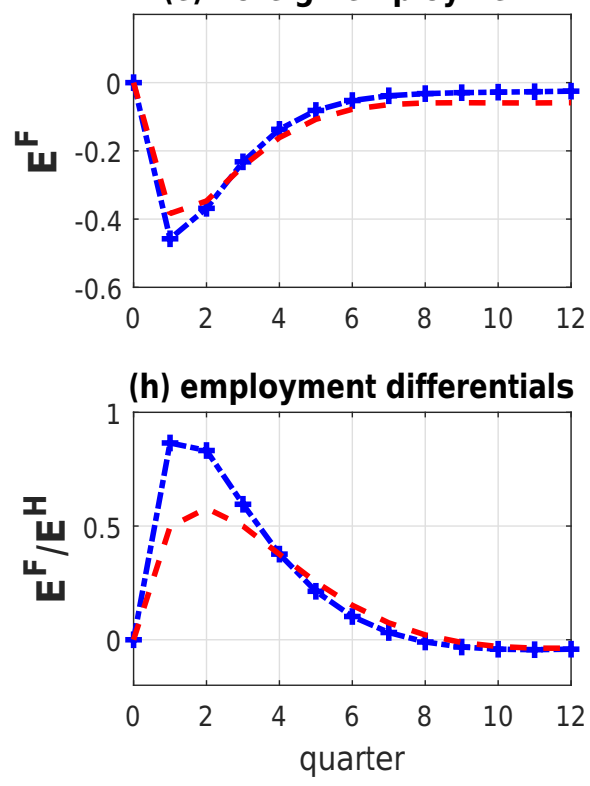

(c) Home R\&D

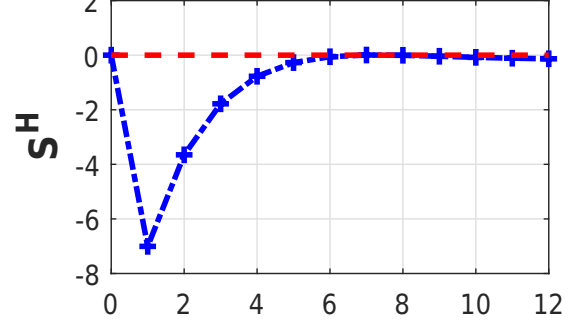

(f) Foreign $R \& D$

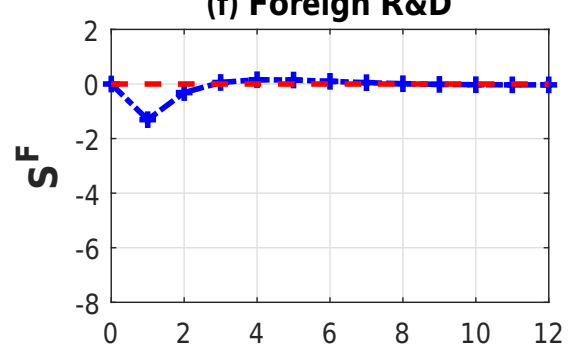

(i) $R \& D$ differentials

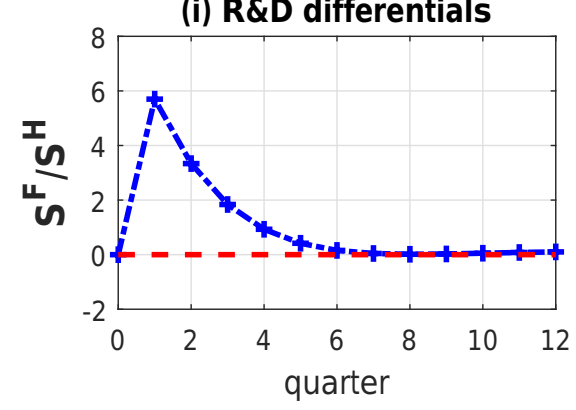

Figure 5: Home risk premium shock (+50 b.p.) 
(a) Home Output

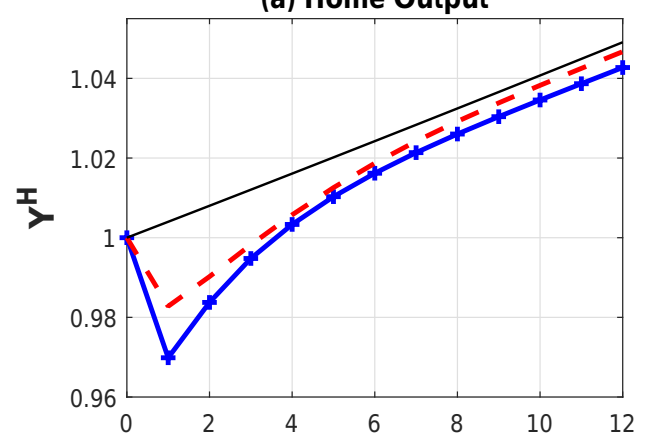

$\stackrel{ \pm}{ \pm}$

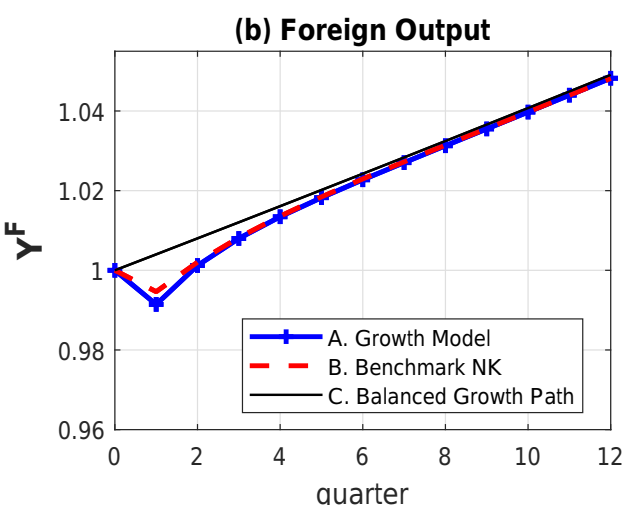

(c) Home TFP

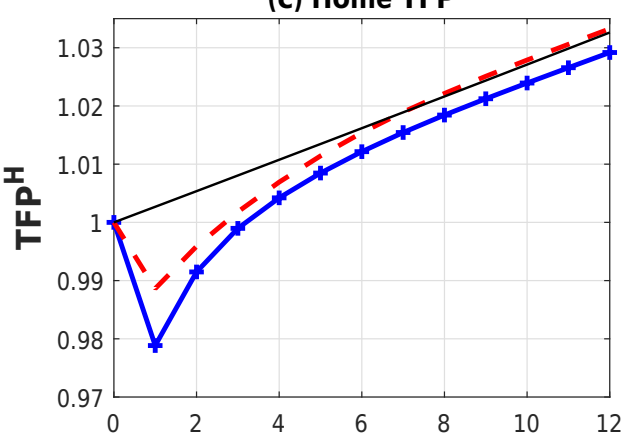

(d) Foreign TFP

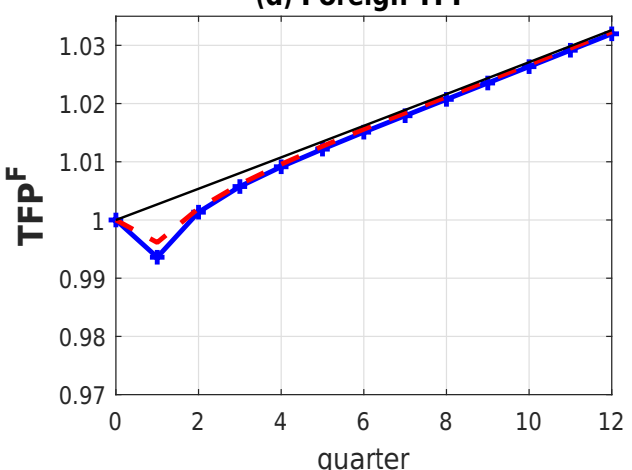

(e) Relative Output

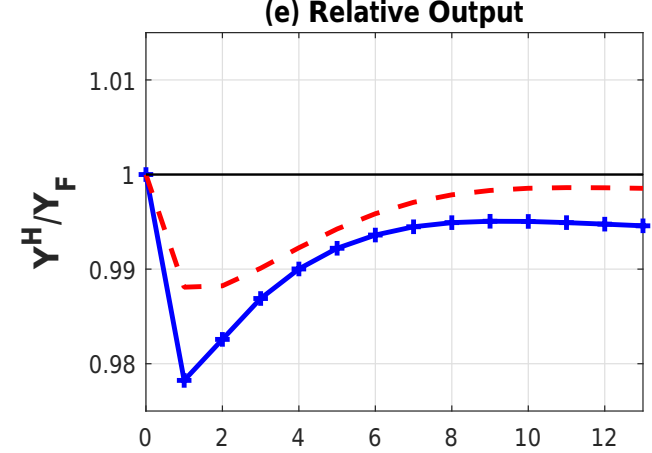

(f) RER

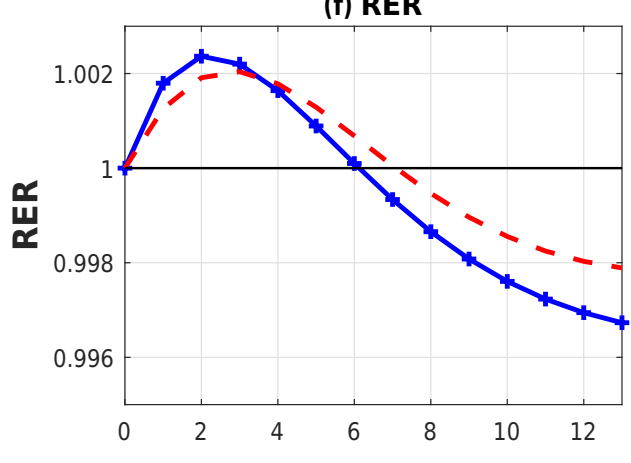

Figure 6: Home risk premium shock, output and TFP dynamics 
(a) Home employment

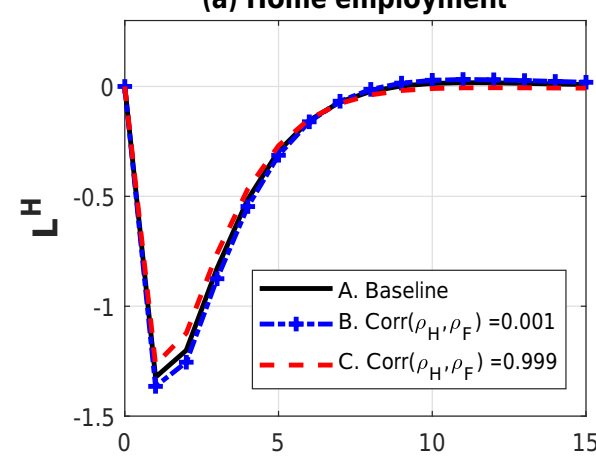

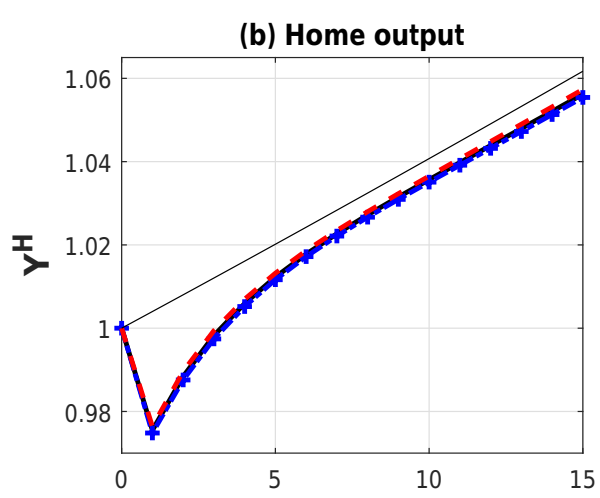
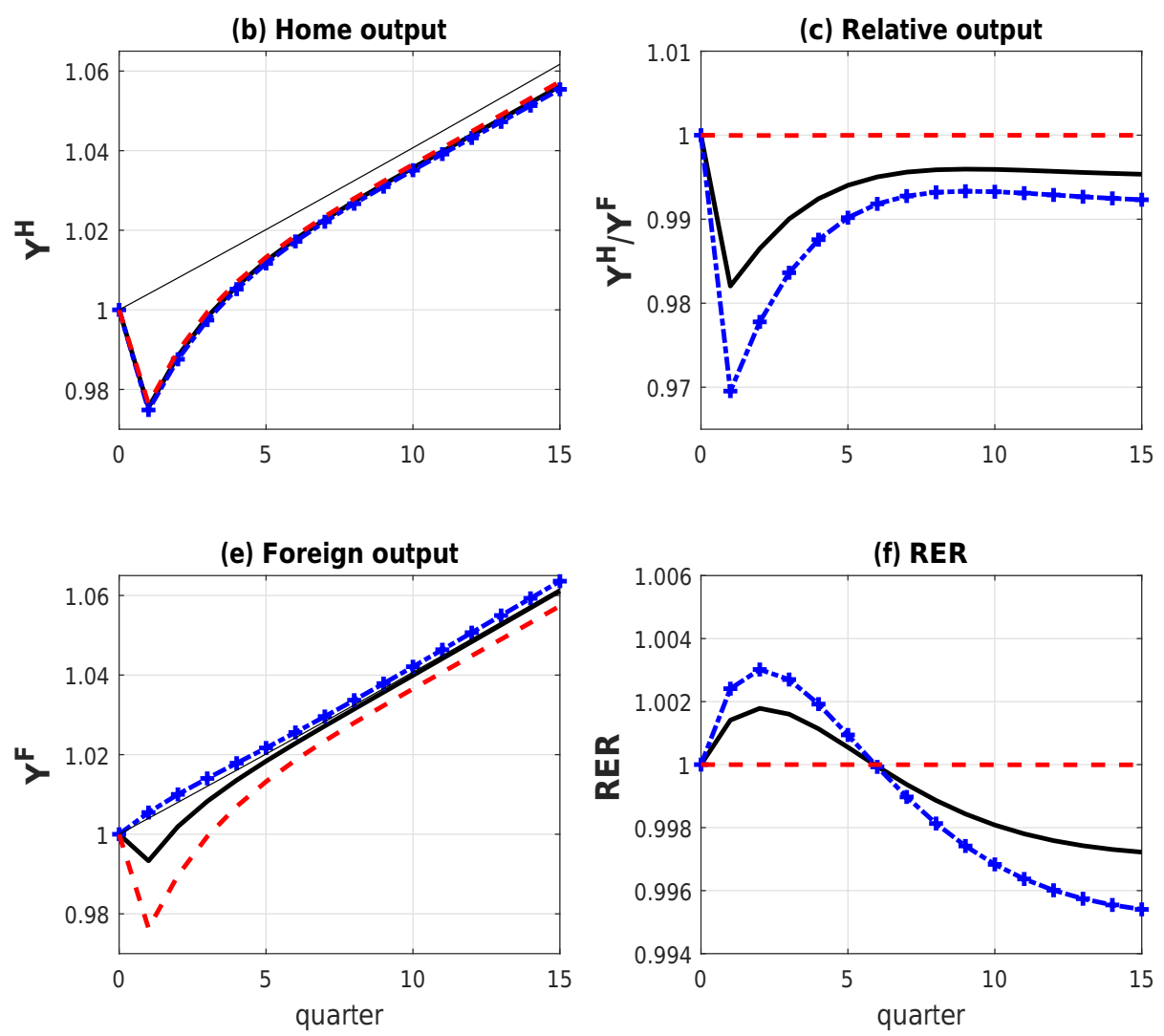

Figure 7: Risk premium spillovers and income divergence 

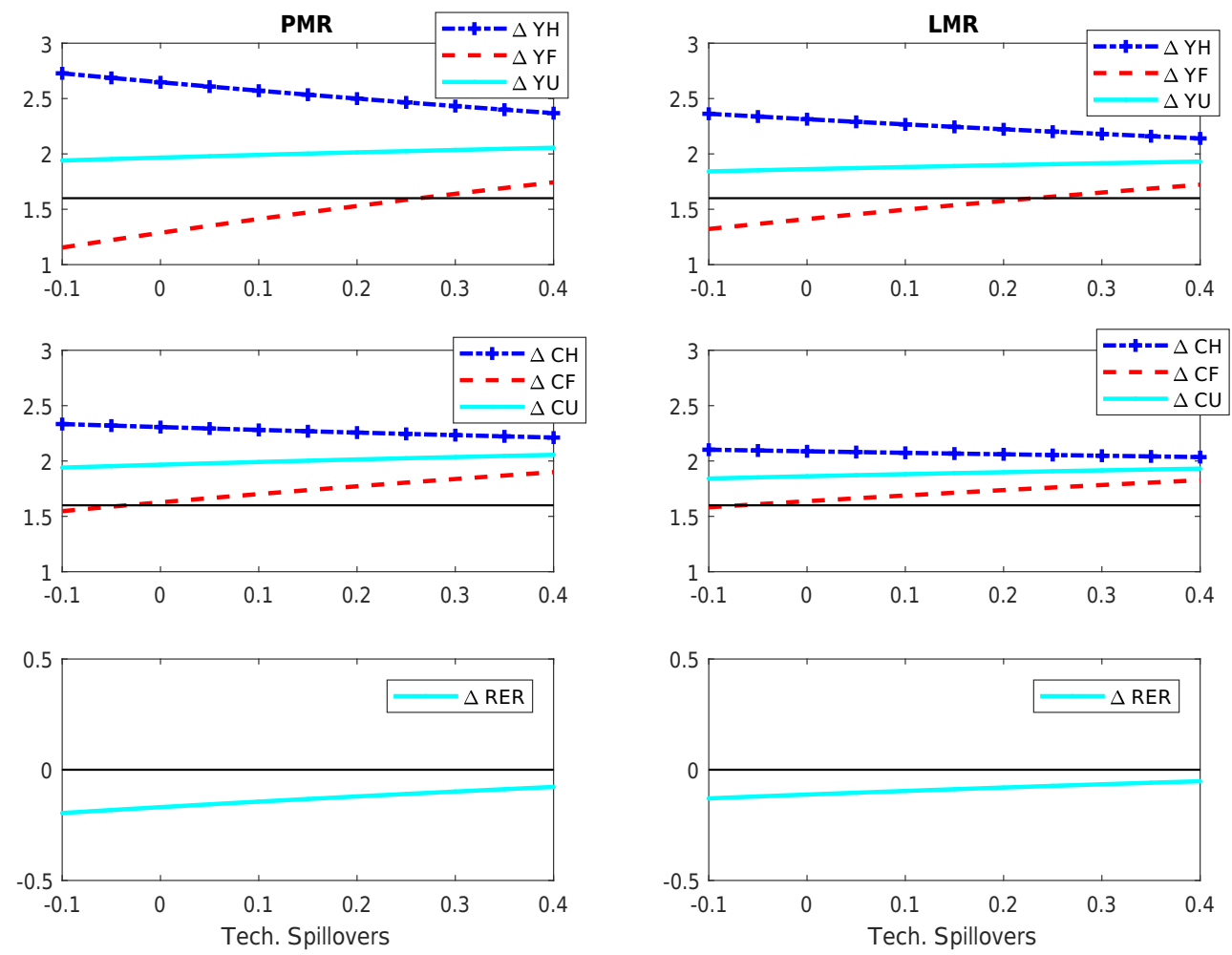

Figure 8: Asymmetric reforms and long run dynamics

This graph shows how the steady state growth rates of output, consumption and the real exchange rate change with different values of the technology spillover parameter $\sigma^{R}$.
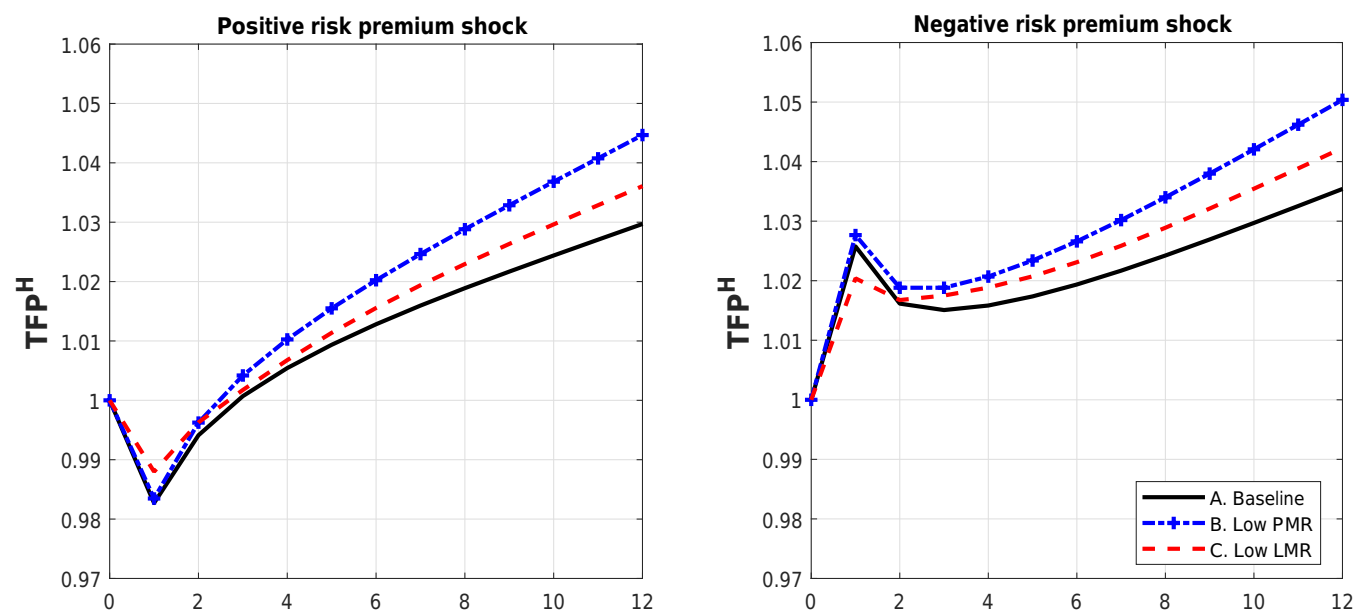

Figure 9: Institutions and risk premium shocks 

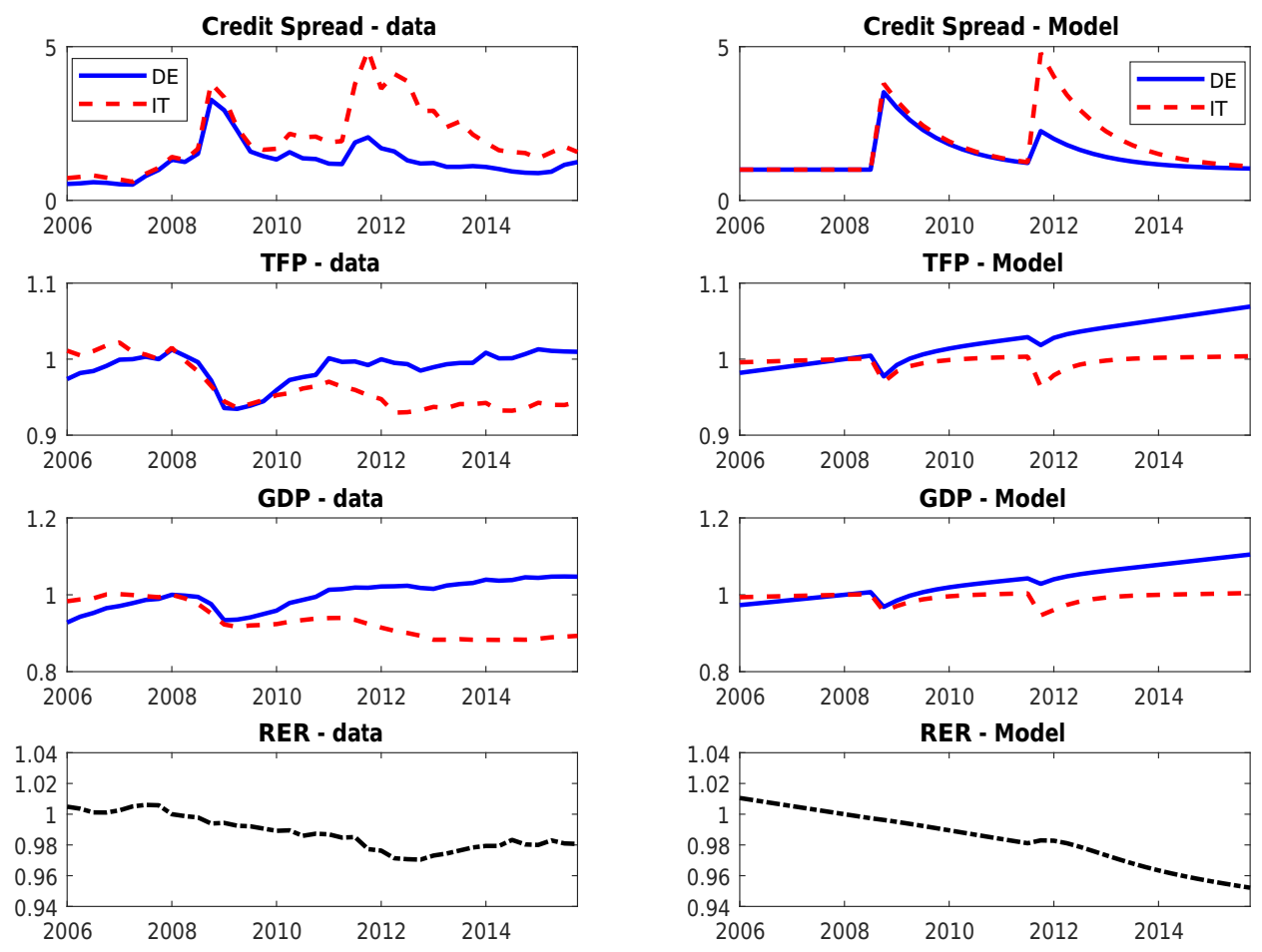

Figure 10: Heterogeneous risk premium shock and real income 2008/11 